Universidad de Lima

Facultad de Comunicación

Carrera de Comunicación

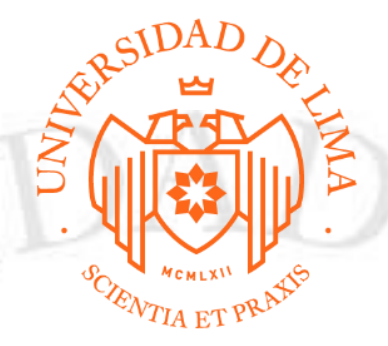

\title{
Proyecto Villa Panamericanos - ganador BESCO
}

Trabajo de Suficiencia Profesional para optar el Título Profesional de Licenciado en Comunicación

Israel Antonio Amoretti Vidal

Código 20122495

Laurita Anabelén Barba Cornejo

Código 20122526

Lima - Perú

2019 


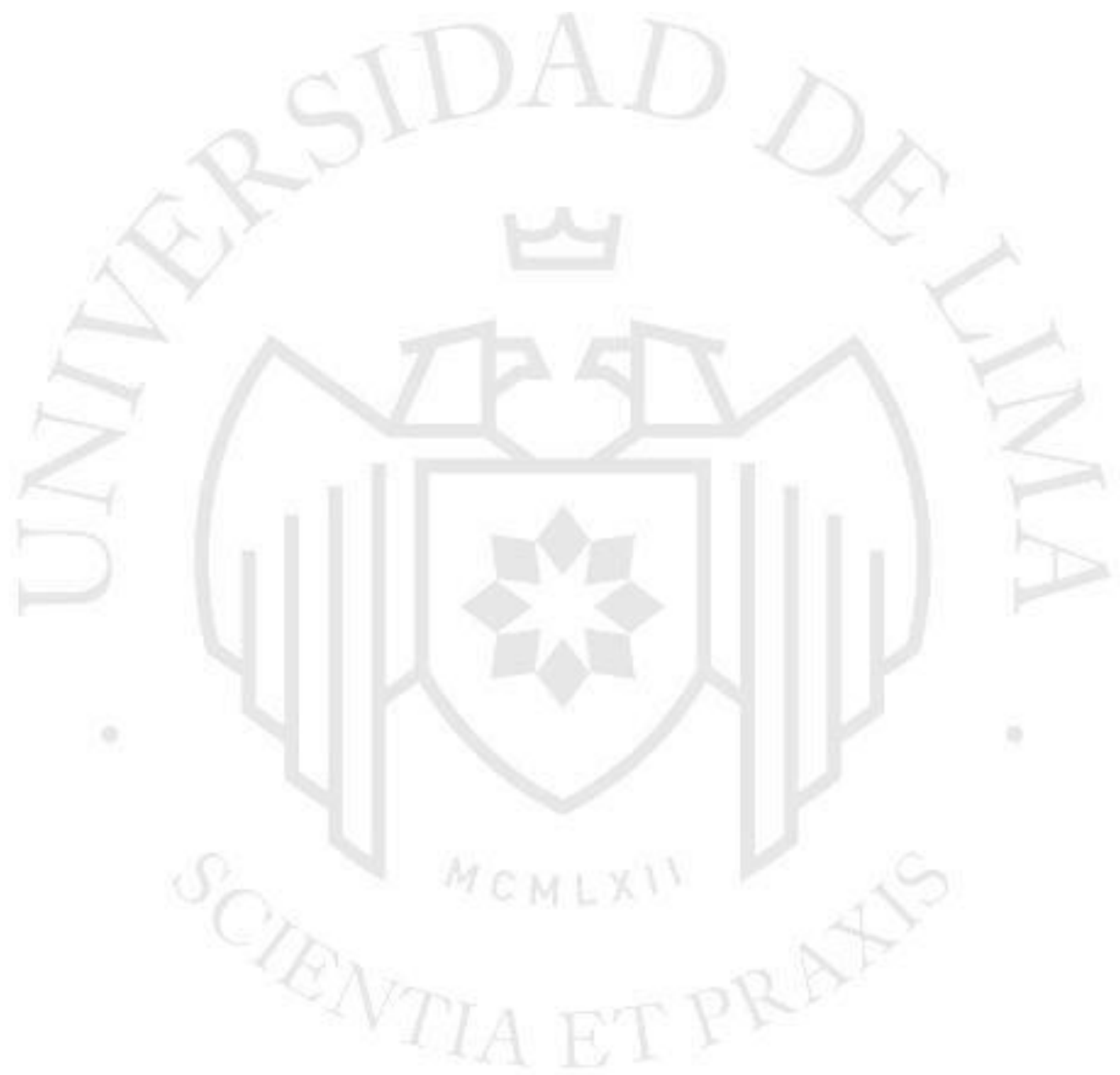




\section{Proyecto Villa Panamericanos -}

ganador BESCO 


\section{ÍNDICE}

\section{RESUMEN}

\section{INTRODUCCIÓN}

\section{CONTEXTO}

\subsection{Político}

1.2 Económico

1.3 Social

1.4 Tecnológico

\section{HALLAZGOS CLAVES}

2.1 Marca

2.2 Competencia

2.3 Mercado

2.4 Precio

2.5 Producto

\section{PÚBLICO OBJETIVO}

3.1 Perfil demográfico y familiar

3.2 Perfil económico y financiero

3.3 Entretenimiento y consumo de medios

3.4 Comportamiento tecnológico

3.5 Compras

3.6 Encuestas

3.7 Buyer persona

4. MARCA

4.1 Posicionamiento

4.2 Posicionamiento

4.3 Promesa

4.4 Ventaja Diferencial

4.5 Reason why

4.6 Tono de comunicación

4.7 Misión y visión de marca 
4.8 Arquitectura de marca

\section{IMAGEN DE MARCA}

5.1 Logo

5.2 Colores

5.3 Manual de marca

6. CAMPAÑA

6.1 Objetivos

6.1.1 Objetivos de Marketing

6.1.2 Objetivos de Comunicación

6.2 Estrategia creativa

6.2.1 Concepto

6.2.2 Idea

6.2.3 Pilares de Comunicación

6.3 Estrategia de medios

6.3.1 Ecosistema de Medios

\subsubsection{DIGITAL}

6.3.1.1.1 FACEBOOK

6.3.1.1.2 INSTAGRAM

6.3.1.1.3 YOUTUBE

6.3.1.1.4 INFLUENCERS

6.3.1.2 ATL

6.3.1.2.1 TV

6.3.1.2.2 Radio

6.3.1.2.2 $\mathrm{OOH}$

\subsubsection{PUNTO DE VENTA}

6.3.2 Etapa de lanzamiento

7. DISTRIBUCIÓN DE INVERSIÓN DE CAMPAÑA

8. SUSTENTO DE PRESUPUESTO

9. CONCLUSIONES

10. RECOMENDACIONES

11. REFERENCIAS 
12. ANEXOS

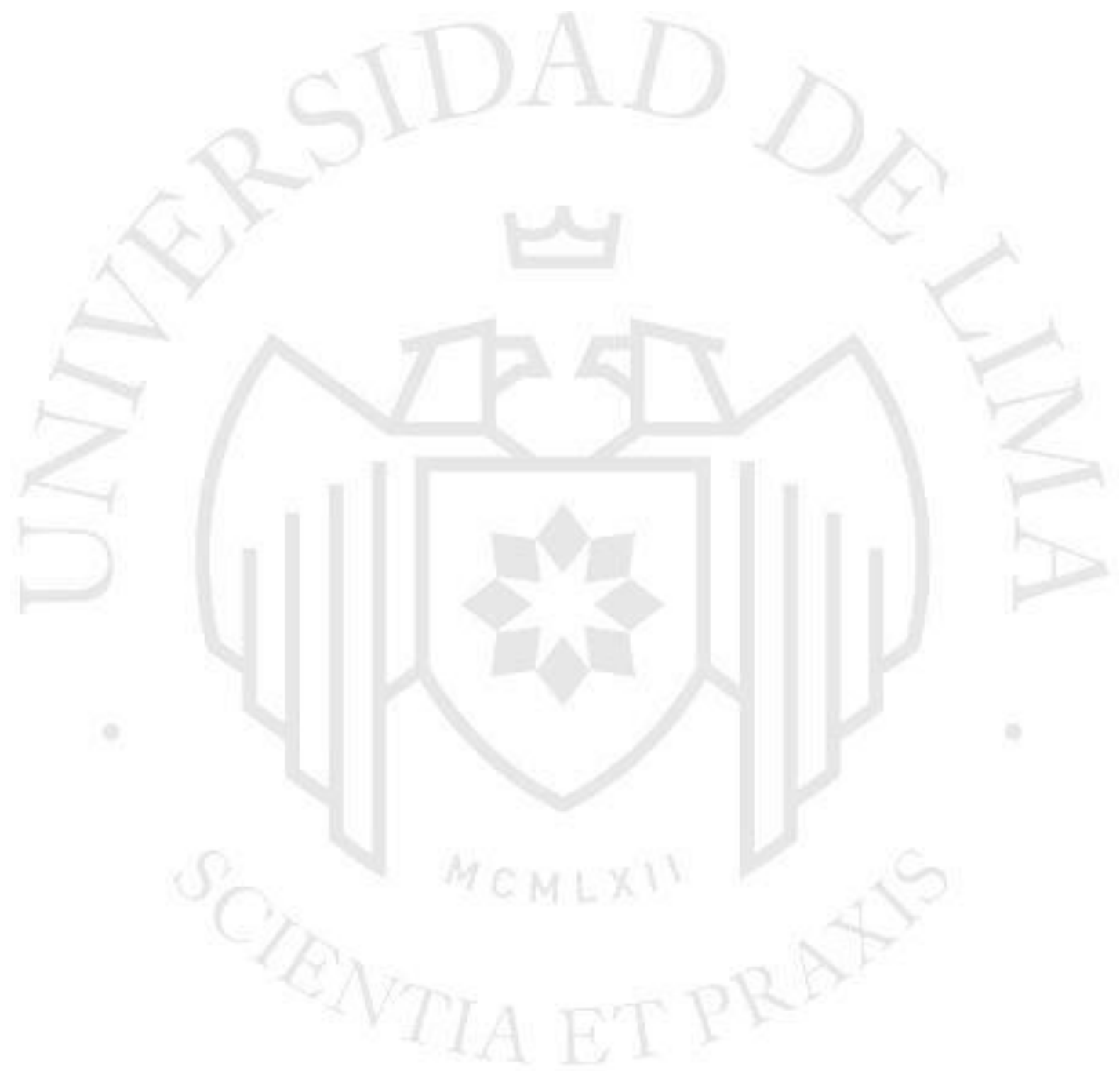




\section{ÍNDICE DE TABLAS}

Tabla 1. Matriz de Perfil Competitivo (MPC)

Tabla 2. Benchmark de inmobiliarias con atributos ecológicos y ahorrativos.

Tabla 3. Elaboración propia/ Adondevivir / Urbania Tabla 4. Elaboración propia/ Adondevivir / Urbania Tabla 5. Elaboración propia/ Adondevivir / Urbania Tabla 6. Elaboración propia/ Adondevivir / Urbania Tabla 7. Esencia de Marca. Elaboración propia Tabla 8.Pilares de Comunicación. Elaboración propia Tabla 9.Estrategia de Medios. Elaboración propia 


\section{ÍNDICE DE FIGURAS}

\section{FIGURAS}

Figura 1. Facebook Perú 21 Panamericanos(2019)

Figura 2 Interés de compra de un departamento en los próximos años (BBVA Research)

Figura 3. Oferta disponible de departamentos (BBVA Research)

Figura 4. Venta de departamentos nuevos. (BBVA Research)

Figura 5. Precio promedio m2. Ventas por distrito ADI (2018)

Figura 6. Niveles de producto. Elaboración propia

Figura 7. ¿Cuál sería tu principal motivación para comprar un departamento? Elaboración propia

Figura 8. Enumera en orden lo que considerarías importante al adquirir un departamento sabiendo que 1 (menos importante) y 6 (más importante). Elaboración propia

Figura 9 ¿Cómo calificarías a estos departamentos si se encuentran en Villa El Salvador? Elaboración propia

Figura 10. Recordando que en la "Villa del Atleta” viven los campeones de los panamericanos, ¿te gustaría vivir en esta villa? Elaboración propia

Figura 11 ¿ Cómo te gustaría que se llame este proyecto? Elaboración propia

Figura 12 ¿ De qué manera prefieres enterarte de las ventas de estos departamentos? Elaboración propia

Figura 13 Buyer persona Elaboración propia

Figura 14 Medios tradicionales y digitales. IPSOS (2018)

Figura 15 Consumo de Medios tradicionales y digitales. IPSOS (2018)

Figura 16 Nivel de atención de consumidores. ARELLANO (2018)

Figura 17.Promedio Semanal Medios tradicionales IPSOS(2018)

Figura 18. Perfil del consumidor. IPSOS(2018)

Figura 19. Atributos de canales de TV Nacional. IPSOS(2018)

Figura 20.Perfil de consumidores. IPSOS(2018)

Figura 21.Consumo de medios digitales. IPSOS(2018) 
Figura 22.Perfil de Consumidores-Facebook. IPSOS(2018)

Figura 23.Perfil de Consumidores- Youtube. IPSOS(2018)

Figura 24.Perfil de Consumidores- Instagram. IPSOS(2018)

Figura 25.Frecuencia consumo TV. IPSOS(2018)

Figura 26. Share de Inversión de la Campaña. Elaboración propia 


\section{RESUMEN EN ESPAÑOL}

En este trabajo se desarrolla la propuesta de comunicación del proyecto Villa Panamericanos de BESCO Emprendedor, un condominio en donde viven los campeones peruanos de los pana y parapanamericanos. Los departamentos son ahorrativos en agua, energía y además son inclusivos. Están dirigidos a jóvenes adultos progresistas del NSE C y D.

\section{Palabras clave: (Inmobiliaria, publicidad, juegos panamericanos)}

\section{RESUMEN EN INGLÉS}

In this proposal, it's developed the comuniccation concept of Villa Panamericanos of BESCO Emprendedor, which is a condominium where peruvian champions of Pana and

Parapanamericans live. The departments are saving on water, energy and also are inclusive. The target are young progressive adults of socio-economic status $C$ and $D$.

Keywords: (real state, advertisement, panamerican games) 


\section{INTRODUCCIÓN}

Lanzaremos al mercado una nueva línea de negocios llamada BESCO Emprendedor, el cual tiene como principal finalidad vender los departamentos de Villa Panamericanos. Realizamos el branding y concepto creativo para su campaña. además de determinar los medios a usar.

La propuesta de BESCO Emprendedor se comunicará tanto en ATL, OOH, Digital, BTL y Punto de Venta en una etapa de lanzamiento.

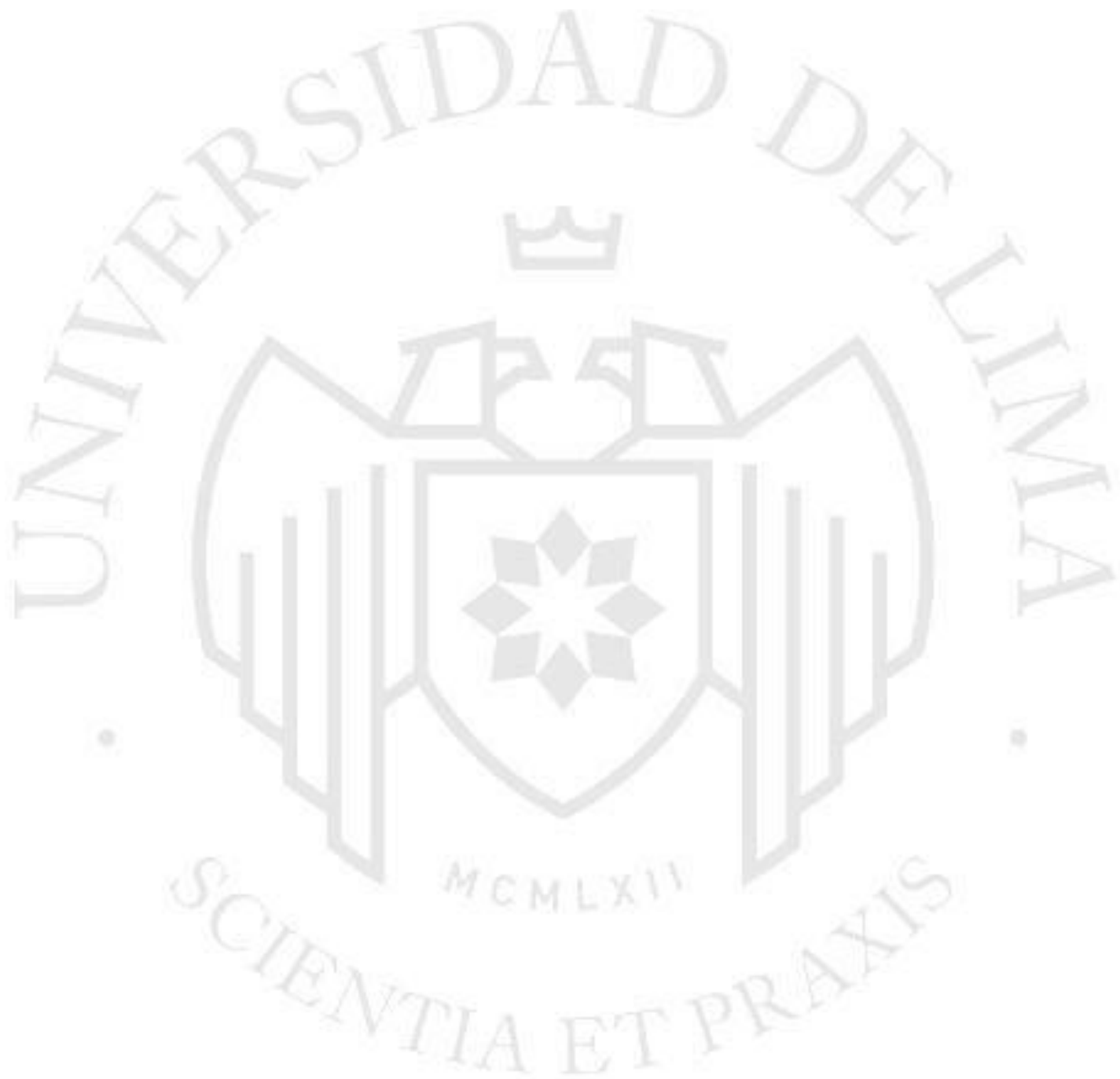

1. CONTEXTO

\subsection{Político}


La realización de los Juegos Panamericanos y Parapanamericanos 2019, uno de los eventos deportivos más importantes del mundo debido a la gran convocatoria que tiene en el mundo del deporte fue todo un reto para el país.

Desde sus inicios, como se recuerda, hubo mucha controversia ya que en marzo del 2017 el Partido Aprista presentó un proyecto de ley para cancelar los Juegos Panamericanos, a fin de destinar el fondo de las obras al norte del país, afectado por el Fenómeno El Niño.

Sin embargo, Carlos Neuhaus Tudela, presidente de la Copal, recalcó que los Juegos Panamericanos 2019 se realizarían en nuestro país y que se estaba trabajando de manera intensa para cumplir con el compromiso asumido por el gobierno peruano. "Pese a quien le pese, vamos a tener Juegos Panamericanos y Parapanamericanos. Estamos trabajando de manera intensa. Esto va a permitir apoyar el deporte. Los Juegos es un grato pretexto para que se involucren todos en el deporte”, indicó el máximo representante del Comité Organizador de los Juegos Panamericanos y Parapanamericanos Lima 2019 (El Comercio, 2019)

Por otro lado, los días más difíciles de nuestra situación política coincidieron con la realización de los Juegos Panamericanos donde el presidente de la República anunciaba su proyecto para adelantar elecciones, la oposición del Congreso mientras Gladys Tejeda, 'Piccolo' Clemente, Diego Elías, Cristhian Pacheco, Natalia Cuglievan, Lucca Mesinas, Daniella Rosas y otros héroes deportivos del país obtenían grandes triunfos para nuestro país ( Correo, 2019)

Martín Vizcarra quien no ha recibido últimamente la aceptación del pueblo peruano aprovechó los triunfos de nuestros deportistas además de tomarse foto con ellos lo que generó rechazo por parte de algunos congresistas. Como por ejemplo, la congresista Yeni Vilcatoma en Twitter lo llamó "metiche" y el "querer colgarse de los deportistas". Sin embargo recibió el apoyo de algunos deportistas como el extenista Luis Horna quien comentó: "Martín Vizcarra estuvo presente desde el principio y ahora ustedes, que no generaron más que problemas, están listos para crear cosas negativas. Destruyan lo que quieran, pero no se metan con el deporte”. 
Asimismo, las personas no olvidan que unos meses atrás también los congresistas fujimoristas querían cancelar los Juegos Panamericanos. Por otro lado, muchos consideraban que la realización de los Juegos Panamericanos "cambiarían positivamente" la forma en la que se "disfrutan" los eventos deportivos en el Perú.

"Quiero hacer referencia al gran evento que se está llevando adelante en nuestro país. Los décimo octavos Juegos Panamericanos y Parapanamericanos, un evento que nos llena de orgullo peruano [...] Imaginen lo que hubiese pasado si hacíamos caso a los predicadores del 'no se puede', imaginen si hubiésemos hecho caso a esa máquina de impedir que se hagan las cosas", señaló el presidente de la República (Gestión, 2019).

Finalmente, respecto a leyes que favorecen la vivienda, una reciente es "Renta Joven", el cual ofrece un monto subsidio de 500 soles por alquiler de una vivienda en 5 años y es dirigido a jóvenes adultos que tengan un ingreso familiar no mayor a S/3500.

\subsection{Económico}

El evento tuvo un impacto positivo en la economía alrededor de S/5.043 millones, lo que equivale a un $0.7 \%$ del Producto Bruto Interno (PBI) (El Comercio, 2019)

En el ámbito laboral, el impacto también ha sido significativo. Según “Amalia Moreno, secretaria ejecutiva de la Copal, afirma que la organización contrató alrededor de 2.000 trabajadores.” (El Comercio, 2019)

Asimismo, se contrató a 300 pequeñas y microempresas y a unos 3000 proveedores. "Si a ello se suma el número de empleos directos generados por el gasto en inversión y el número de empleos inducidos, los juegos a la fecha han generado alrededor de $517 \mathrm{mil}$ puestos de trabajo.” (El Comercio, 2019)

El sector construcción tiene un gran impacto en la economía. "Este sector se divide en dos grandes subsectores: el inmobiliario, una actividad exclusivamente privada, y el de infraestructura, donde interviene tanto el sector público como el privado." (Macro Consult, 2019). 
Por otro lado, hay un crecimiento de la demanda de departamentos de los sectores emergentes de la población por el aumento de sus ingresos, como las formas de financiamiento. "Adquirir una vivienda es más fácil debido a las condiciones favorables del mercado" (BBVA, 2008). Asimismo, el número de créditos de Mivivienda ha aumentado en un $47.4 \%$ en relación al año anterior (El Comercio, 2019)

Por otro lado, el sector Financiero y Seguros aumentó en 4\%. "Esto se explicó por el aumento de créditos a corporaciones, grandes, medianas y pequeñas empresas (4.83\%), y por el crecimiento de los créditos de consumo (9.61\%) y los créditos hipotecarios (7.16\%). Los depósitos totales también tuvieron un buen desempeño con 6.91\%”. (El Comercio, 2019)

\subsection{Social}

Miles de turistas llegarán a nuestro país para presenciar los Juegos Panamericanos y Parapanamericanos siendo la perfecta ocasión para mostrar al mundo que nuestro desarrollo no solo involucra lo económico, sino también lo social y cultural.

Más allá de la importancia de estas competencias, los Juegos Panamericanos son el evento más grande que se haya dado antes en el Perú y no solamente por la cantidad de deportistas y espectadores que llegarán al país, sino también por la cobertura mediática que tendrá, lo que hará que nuestra capital sea vista por millones de personas en el mundo (Arellano, 2019)

Asimismo, se sabe que cerca de 1,000 millones de personas siguieron la apertura y clausura de los Juegos Panamericanos. "Los Juegos Panamericanos Lima 2019 han marcado un gran hito en la historia del deporte internacional.” (E1 Peruano, 2019)

Asimismo, 7 de cada 10 limeños vieron la ceremonia. "El 86\% cree que la inauguración reflejó lo mejor del Perú tradicional y moderno (Logo) y el $87 \%$ opina que nunca se ha 
visto un show como el de apertura de los primeros Juegos Panamericanos que se realizan en la capital" (El Comercio, 2019)

Por otro lado, el sentir de la población fue favorable en un $94 \%$ por los juegos panamericanos. Inclusive el $83 \%$ considero que mostraron respeto por los carriles exclusivos, y "el 78\% cree un evento como este "hace que los peruanos respeten las normas" (El Comercio, 2019)

La ceremonia de clausura se vivió al máximo en las redes sociales con sentimientos positivos de $34 \%$ en Twitter. Asimismo, esta red social alcanzo el primer lugar en tendencias en seis horas. "Los hashtags más empleados fueron \#Lima2019, \#JuegosPanamericanos2019, \#Clausura2019 y \#JugamosTodos.” (Andina, 2019).

Por otro lado, existen comentarios positivos sobre el premio u obsequio de departamentos que recibieron los peruanos ganadores de los juegos panamericanos. (Perú 21, 2019) 


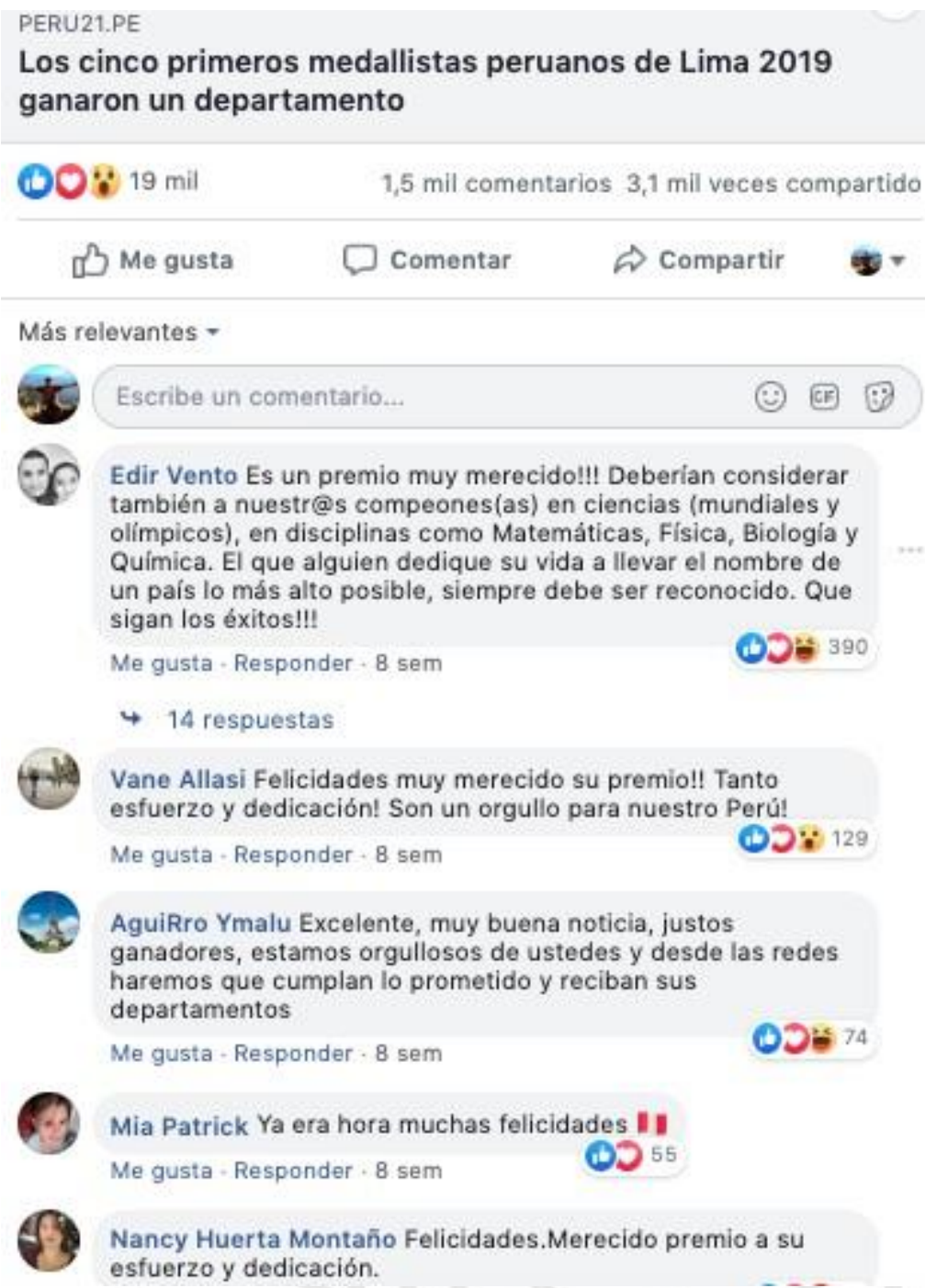

Vane Allasi Felicidades muy merecido su premio!! Tanto esfuerzo y dedicación! Son un orgullo para nuestro Perú!

Nancy Huerta Montaño Felicidades.Merecido premio a su esfuerzo y dedicación.

Figura 1. Facebook Perú 21 Panamericanos(2019)

A lo largo de estos años, el tipo de vivienda familiar ha cambiado radicalmente lo que representa un gran desafío de adaptación al sector de la construcción.

Antes se hablaba del "sueño de la casa propia", que implicaba tener tu propia vivienda: amplia y en el primer piso pues a pesar de la existencia de edificios populares, buscar departamento era una opción secundaria para la mayoría que incluso veían en los alrededores la oportunidad de hallar un terreno donde construir. "Empezaron a llegar allí parejas que habían crecido en el segundo y tercer piso de la casa de sus padres, que tuvieron que aprender a convivir codo a codo, por primera vez, con personas distintas a 
sus propias familias. ¿El tamaño? ¡Pequeñísimo!, decían, pues eran "solo” 120 metros cuadrados, incluyendo por cierto el "cuarto de servicio". (Arellano, 2019)

Por otro lado, la población empezó a aceptar los departamentos situados en edificios altos. donde "la esposa moderna que trabaja fuera, aceptó un tamaño mejor (70 o 60 metros) lo cual bastaba si estaban bien situados y distribuidos-, pues ya no se cocina tanto en casa y no hay empleada para mantenerla." (Arellano, 2019)

Por otro lado, los paradigmas han cambiado y comienza a desaparecer el concepto de "La casa para toda la vida", que transformará más a la industria de la construcción, pues las familias comenzarán a vender y comprar sus viviendas según sus necesidades del momento" (Arellano, 2019)

Por ello, actualmente existe una tendencia y demanda de departamentos pequeños desde $26 \mathrm{~m} 2$. "Hace tres años la oferta de departamentos pequeños viene en aumento, siendo dirigida a los jóvenes y adultos profesionales" (La República, 2019)

Asimismo, los departamentos de menos de $80 \mathrm{~m} 2$ son los más vendidos según la Asociación de Desarrolladores Inmobiliarios del Perú (ADI Perú). "Las viviendas que vienen siendo más solicitadas en Lima son aquellas de entre 51 y 80 metros cuadrados (m2). Así, se vendieron 5.945 unidades habitacionales de este tipo entre enero y julio del 2019.” (república)

Asimismo, las áreas comunes tienen mayor relevancia. "Ante la falta de suelos, Lima está creciendo "hacia arriba". Esta es una realidad que no podemos negar y a la cual el mercado inmobiliario se ha adaptado de diferentes maneras. Asimismo, con un ritmo de vida mucho más intenso, con una generación que prioriza la ubicación y las comodidades al alcance de la mano, los espacios comunes han cobrado un protagonismo sin precedentes." (nexo inmobiliario) 
Finalmente, los departamentos eco amigables han despertado la conciencia ambiental de las inmobiliarias y compradores. La “...tendencia que se empezó a gestar en el 2018 es la construcción de departamentos y viviendas que incorporan ciertos criterios de sostenibilidad en su diseño y construcción, lo que permite disminuir su impacto en el medio ambiente. Estos procesos te permiten ahorrar en energía eléctrica y agua. En promedio, tus gastos mensuales se verán reducidos hasta en un 30\%.”. (Abril - Grupo Inmobiliario, 2019)

\subsection{Tecnológico}

La implantación de las últimas tecnologías en el sector inmobiliario avanza sin detenerse. Las innovaciones afectan a todos los procesos del sector, desde el diseño de los espacios hasta la forma de captación de clientes para la venta y alquiler de viviendas. Es lo que se conoce como 'proptech', la industria tecnológica que contribuye a crear valor añadido en el sector inmobiliario (Guinotprunera-Serves Immobiliaris, 2019)

Asimismo, el uso de la realidad virtual para la visualización y comercialización de los inmuebles, software de gestión, sistemas domóticos o el internet de las cosas se han convertido en herramientas indispensables en el sector, aunque el potencial de crecimiento de estas nuevas tecnologías en el sector es, según los analistas es impresionante. (PropTech Latam, 2019)

El mercado está empezando a considerar el impacto que está causando la tecnología para este sector. Este año, en nuestro país se organizó el evento PropTech Latam Workday con importantes temas sobre negocios, inversiones y desarrollo de nuevas tecnologías.

Otro evento que se sumó este año fue Expo Oficinas 2019. El cual congregó a los mejores exponentes, marcas y especialistas en mobiliarios, arquitectura, diseño, tecnología, estilo de vida y tendencias. 
Este importante evento, que se realiza por quinto año consecutivo en nuestro país, contará con más de 50 stands con las mejores marcas del rubro y salones temáticos dedicados a la tecnología, el diseño mobiliario, la arquitectura y el sector inmobiliario, creado por empresas y empresario del más alto nivel (Perú 21, 2019)

Por otro lado, el uso de tecnologías como el Big data y herramientas como el CRM están transformando el sector desde la experiencia con el cliente hasta la toma de decisiones de las inmobiliarias (La República, 2019)

Los medios digitales son una herramienta importante para la compra y venta de un departamento.

"La integración del sector inmobiliario con el mundo digital se hace inevitable. Hoy, las personas antes de tomar la decisión de adquirir un departamento recurren a internet, en donde investigan sobre los proyectos, hacen recorridos virtuales (si los portales de las inmobiliarias ofrecen esta herramienta) y están al tanto de los comentarios de anteriores clientes.” (Abril - grupo inmobiliario, 2019)

\section{Hallazgos Claves}

\subsection{Marca}

BESCO es una empresa peruana con más de 19 años en el mercado, su experiencia en el rubro inmobiliario y de construcción ha consolidado una imagen emprendedora, confiable y exitosa; dedicada a construir bienestar para todos sus clientes.

Cabe resaltar que BESCO es una marca reconocida por su garantía al ofrecer calidad en todos los proyectos ejecutados, manteniendo de principio a fin una adecuada relación entre socios y clientes dentro de los convenios suscritos, eficiencia a través de una interacción fluida y constante entre todas las áreas de la empresa, lo que permite adaptarse a las demandas del mercado en tiempo real y seguridad. 
Asimismo, dispone de un patrimonio de más de 85 millones de soles, habiendo crecido a una tasa promedio anual de $31 \%$ en los últimos 6 años. Además, de contribuir al desarrollo del país con inversiones y creación de puestos de trabajo, habiendo aportado más de 37 millones de soles en impuestos desde su fundación.

Como parte de su trayectoria, inició sus operaciones en uno de los proyectos más importantes de la época para la Compañía Minera Antamina, en la construcción y concesión de la carretera Panamericana Norte en el tramo Ancón-Pativilca.

Sin embargo. como contexto de los campeones peruanos de los Panamericanos y Parapanamericanos 2019 se realizará el lanzamiento de una nueva línea de negocio para el cual se eligió el nombre EMPRENDEDOR, palabra que describe una de las características del peruano principalmente por su carácter luchador y de querer superar sus propios límites.

\subsection{Competencia}

\section{Directa}

Según la matriz de perfil competitivo de un estudio de la Universidad del Pacífico, se halló que Besco tiene un promedio ponderado de 2.82 frente a sus competidores, lo cual es en una empresa de tipo seguidor. Además, tiene mayor valor en capacidad tecnológica a un nivel 4 frente a sus competidores. Por otro lado, Besco debe reforzar su participación de mercado y mantener a un nivel 3 o mejorar a un nivel 4 la calidad del producto/servicio. 


\begin{tabular}{|c|c|c|c|c|c|c|c|c|c|c|}
\hline \multicolumn{11}{|c|}{ Formato de la Matriz de Perfil Competitivo (MPC) } \\
\hline & & & \multicolumn{2}{|c|}{ BESCO } & \multicolumn{2}{|c|}{ VIVA GYM } & \multicolumn{2}{|c|}{ LÍDER } & \multicolumn{2}{|c|}{ LOS PORTALES } \\
\hline \multicolumn{2}{|c|}{$\begin{array}{l}\text { Factores Clave de } \\
\text { Exito }\end{array}$} & \multirow{2}{*}{\begin{tabular}{|c|} 
Peso \\
0.03
\end{tabular}} & \multirow{2}{*}{$\begin{array}{c}\text { Valor } \\
1\end{array}$} & \multirow{2}{*}{$\begin{array}{c}\text { Ponderación } \\
0.03\end{array}$} & \multirow{2}{*}{$\begin{array}{c}\text { Valor } \\
4\end{array}$} & \multirow{2}{*}{\begin{tabular}{|c|} 
Ponderación \\
0.12 \\
\end{tabular}} & \multirow{2}{*}{$\begin{array}{c}\text { Valor } \\
3\end{array}$} & \multirow{2}{*}{$\begin{array}{c}\text { Ponderación } \\
0.09\end{array}$} & \multirow{2}{*}{$\begin{array}{c}\text { Valor } \\
3\end{array}$} & \multirow{2}{*}{$\begin{array}{c}\text { Ponderación } \\
0.09\end{array}$} \\
\hline 1 & $\begin{array}{l}\text { Participación del } \\
\text { mercado }\end{array}$ & & & & & & & & & \\
\hline 2 & $\begin{array}{l}\text { Capacidad } \\
\text { financiera }\end{array}$ & 0.20 & 3 & 0.60 & 4 & 0.80 & 3 & 0.60 & 3 & 0.60 \\
\hline 3 & $\begin{array}{l}\text { Capacidad de } \\
\text { almacenamiento }\end{array}$ & 0.12 & 1 & 0.12 & 3 & 0.36 & 3 & 0.36 & 3 & 0.36 \\
\hline 4 & $\begin{array}{l}\text { Calidad del } \\
\text { producto / } \\
\text { servicio } \\
\end{array}$ & 0.03 & 3 & 0.09 & 3 & 0.09 & 3 & 0.09 & 3 & 0.09 \\
\hline 5 & $\begin{array}{l}\text { Capacidad } \\
\text { tecnológica }\end{array}$ & 0.20 & 4 & 0.80 & 3 & 0.60 & 3 & 0.60 & 3 & 0.60 \\
\hline 6 & $\begin{array}{l}\text { Gestión de } \\
\text { trámites de } \\
\text { licencias }\end{array}$ & 0.12 & 3 & 0.36 & 3 & 0.36 & 3 & 0.36 & 3 & 0.36 \\
\hline 7 & $\begin{array}{l}\text { Alianzas } \\
\text { estratégicas con } \\
\text { otras empresas }\end{array}$ & 0.10 & 3 & 0.30 & 3 & 0.30 & 3 & 0.30 & 3 & 0.30 \\
\hline 8 & $\begin{array}{l}\text { Canales de } \\
\text { ventas }\end{array}$ & 0.03 & 2 & 0.06 & 2 & 0.06 & 3 & 0.09 & 3 & 0.09 \\
\hline 9 & $\begin{array}{l}\text { Inversión en } \\
\text { marketing }\end{array}$ & 0.05 & 2 & 0.10 & 3 & 0.15 & 2 & 0.10 & 2 & 0.10 \\
\hline 10 & $\begin{array}{l}\text { Gestión } \\
\text { contractual / } \\
\text { contratos }\end{array}$ & 0.12 & 3 & 0.36 & 3 & 0.36 & 3 & 0.36 & 3 & 0.36 \\
\hline & Total & 1.00 & & 2.82 & & 3.20 & & 2.95 & & 2.95 \\
\hline
\end{tabular}

Tabla 1. Matriz de Perfil Competittivo (MPC)

BENCHMARK PROYECTOS INMOBILIARIOS - MIVIVIENDA VERDE

\begin{tabular}{|l|l|l|l|}
\hline Inmobiliaria & Ubicación & Área & Compra \\
\hline Paz Centenario S.A. & $\begin{array}{c}\text { Av. Las Lomas km. 6.5 urb. } \\
\text { Villa Club, Carabayllo }\end{array}$ & Desde 66.82 m2 & Desde 159,590 \\
\hline $\begin{array}{l}\text { Los Portales Construye } \\
\text { S.A.C. }\end{array}$ & $\begin{array}{c}\text { Av. Alameda Naña s/n, } \\
\text { Lurigancho, Chosica }\end{array}$ & Desde $57.75 \mathrm{~m}^{2}$ & Desde S/ 148,422 \\
\hline $\begin{array}{l}\text { Desarrollador } \\
\text { Inmobiliario Magbis }\end{array}$ & $\begin{array}{c}\text { Antigua Carretera } \\
\text { Panamericana Sur, Lurín }\end{array}$ & Desde $48.50 \mathrm{~m}^{2}$ & Desde S/ 130,000 \\
\hline Paz Centenario S.A. & $\begin{array}{c}\text { Carretera Panamericana } \\
\text { Norte km 27, Fundo } \\
\text { Gallinazos - Puente Piedra }\end{array}$ & Desde $58.45 \mathrm{~m}^{2}$ & Desde S/ 167,468 \\
\hline Inmobiliaria Ruttini & $\begin{array}{c}\text { Av. Nogales Cdra. 2 Alt. } \\
\text { Km 2.8 Carretera Central, } \\
\text { calle los Ángeles (Ex } \\
\text { Fábrica Campoy) San Juan } \\
\text { de Lurigancho }\end{array}$ & Entre $38.64 \mathrm{~m}^{2}-$ & Desde S/ 123,000 \\
& $\begin{array}{c}78.30 \mathrm{~m}^{2} \\
\end{array}$ & \\
\hline
\end{tabular}

Tabla 2. Benchmark de inmobiliarias con atributos ecológicos y ahorrativos. 


\section{Indirecta}

En nuestro caso estudiado hay cuatro tipos de competencia indirecta: la venta de casas, el alquiler de departamentos, la venta de departamentos de segunda mano y la compra de terrenos( Techo propio)

El primer ítem podemos descartarlo debido a su alto costo. Las casas encontradas en el sector analizado tienen precios por encima de los trescientos mil.

Revisaremos entonces las alternativas siguientes.

a) Venta de departamentos de estreno

Este es un mercado muy activo con una gran variedad de tipos de departamentos en oferta. Los precios de los alquileres están en relación con las áreas de los departamentos, su ubicación y la antigüedad del inmueble.

A pesar de esto los rangos de venta oscilan bastante. La siguiente tabla brinda información acerca de los departamentos de estreno cercanos a la Villa Panamericana

\begin{tabular}{|l|l|l|}
\hline \multicolumn{1}{|c|}{ Ubicación } & \multicolumn{1}{|c|}{ Àrea (m2) } & \multicolumn{1}{c|}{ Compra(\$) } \\
\hline Av.Villa del Mar & $60 \mathrm{~m} 2$ & $184,800(55,000)$ \\
\hline Av Revolución & $60 \mathrm{~m} 2$ & $187,000(55,500)$ \\
\hline Av. El Sol & $86 \mathrm{~m} 2$ & $231,880(68,000)$ \\
\hline Urb. Villa Las Flores & $100 \mathrm{~m} 2$ & $289,000(85,000)$ \\
\hline
\end{tabular}

Tabla 3. Elaboración propia/ Adondevivir / Urbania

b)Venta de departamentos de segunda mano

\begin{tabular}{|l|l|l|}
\hline \multicolumn{1}{|c|}{ Ubicación } & \multicolumn{1}{|c|}{ Àrea (m2) } & \multicolumn{1}{c|}{ Compra(\$) } \\
\hline Av. Los Algarrobos & $59 \mathrm{~m} 2$ & $45,000(151,650)$ \\
\hline Av. El Sol & $62 \mathrm{~m} 2$ & $65,000(219,050)$ \\
\hline Av. Los Algarrobos & $75 \mathrm{~m} 2$ & $77,000(259,490)$ \\
\hline Av. San Juan de Miraflores & $80 \mathrm{~m} 2$ & $85,000(284,000)$ \\
\hline
\end{tabular}

Tabla 4. Elaboración propia/ Adondevivir / Urbania 
c) Alquiler de departamentos

\begin{tabular}{|l|l|l|}
\hline \multicolumn{1}{|c|}{ Ubicación } & \multicolumn{1}{|c|}{ Àrea (m2) } & \multicolumn{1}{c|}{ ALquiler(\$) } \\
\hline Av. Los Algarrobos & $70 \mathrm{~m} 2$ & $1,000(295)$ \\
\hline Av. Revolución & $140 \mathrm{~m} 2$ & $1,400(412)$ \\
\hline
\end{tabular}

Tabla 5. Elaboración propia/ Adondevivir / Urbania

d)Venta de terreno

\begin{tabular}{|l|l|l|}
\hline \multicolumn{1}{|c|}{ Ubicación } & \multicolumn{1}{|c|}{ Àrea $(\mathrm{m} 2)$} & \multicolumn{1}{c|}{ Venta $(\$)$} \\
\hline Av. Mariátegui & $60 \mathrm{~m} 2$ & $144,910(43,000)$ \\
\hline Av Mariano Pastor Sevilla & $80 \mathrm{~m} 2$ & $200,400(60,000)$ \\
\hline Av. Pachacútec & $90 \mathrm{~m} 2$ & $134,800(40,000)$ \\
\hline AV. Pastor Sevilla & $98 \mathrm{~m} 2$ & $181,980(54,000)$ \\
\hline
\end{tabular}

Tabla 6. Elaboración propia/ Adondevivir / Urbania

\subsection{Mercado}

El negocio del sector inmobiliario está en auge. Se proyecta un crecimiento de $9 \%$ en ventas y construcción en el año 2019, según el vicepresidente de la Asociación de Empresas Inmobiliarios del Perú, Ricardo Arbulú. (Nexo inmobiliario). “ De 2 millones de departamentos en demanda en todo el Perú, 1 millón se da en Lima. De este millón, 500 mil son demanda efectiva, es decir, podrán acceder a crédito de compra", detalló. Esta alta demanda efectiva se debe al crecimiento del trabajo formal en el país, que fue de 3.5\% a fines del 2018." (Depolitika.pe)

Por otro lado, según un estudio del BBVA research, la demanda de departamentos excede la oferta disponible en el mercado limeño. 
Interés de compra de un departamento en los próximos dos años (número de hogares)

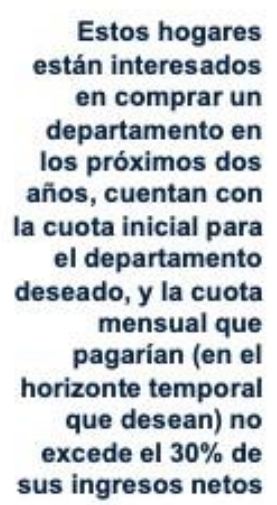

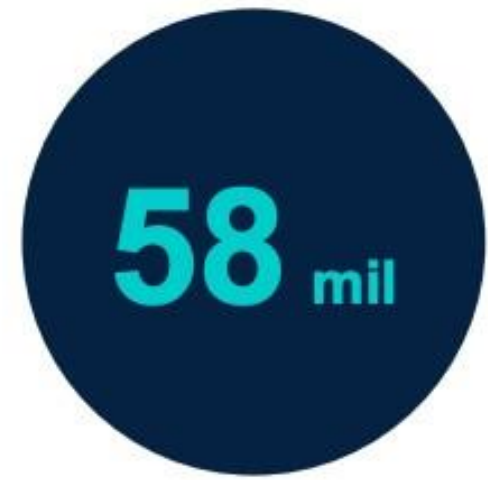

Oferta de departamentos (número de hogares)

Figura 2. Interés de compra de un departamento en los próximos años (BBVA Research)

Asimismo, en este mismo estudio, se detalla la oferta y demanda por precios de departamento:

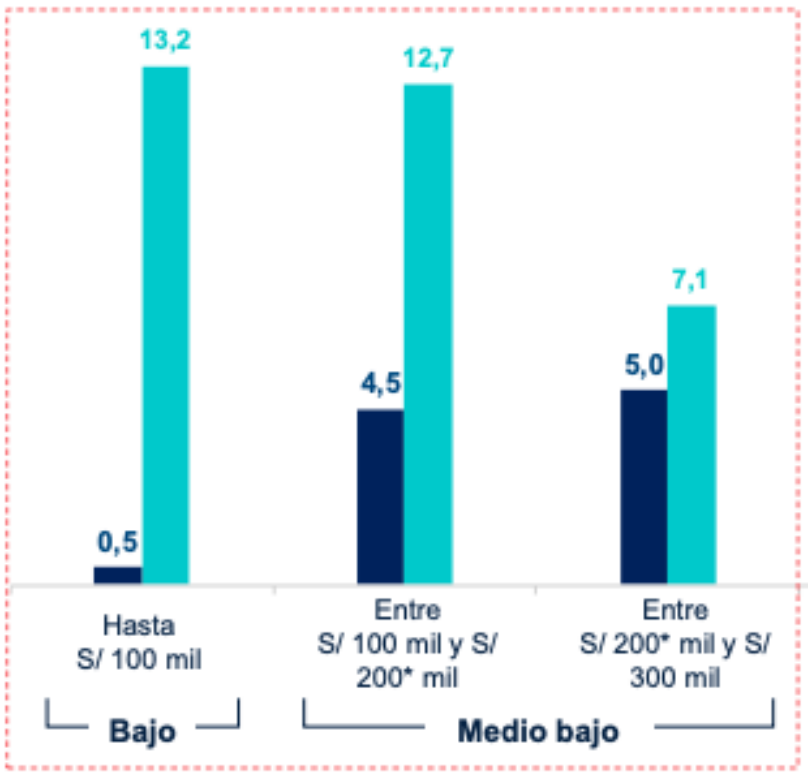

Oferta disponible Intención de compra (demanda)

Figura 3. Oferta disponible de departamentos (BBVA Research)

Además, respecto a las ventas, se estima que "alcanzarán entre 16,5 mil y 17 mil unidades en el año" 


\section{Ventas de departamentos nuevos(1)}

(en unidades)

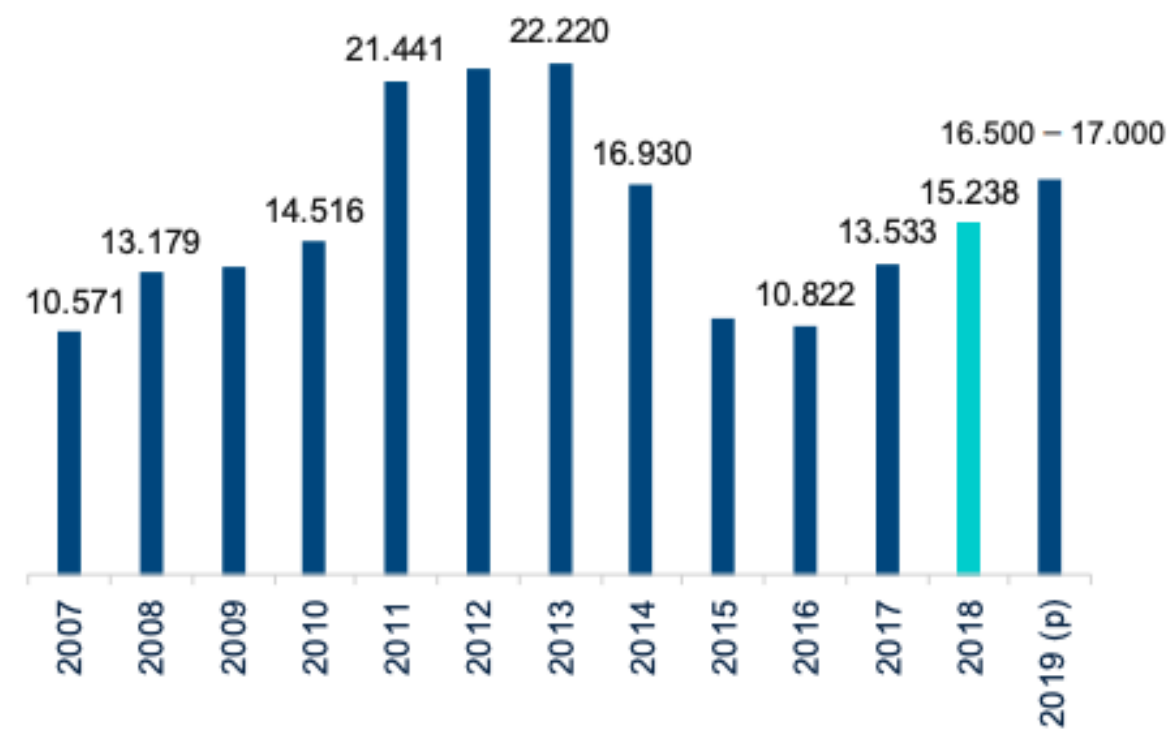

(p) Proyección.

(1) Comprende a 49 distritos de Lima-Callao. El $98 \%$ de las ventas corresponde a departamentos nuevos; lo restante corresponde a casas nuevas. La información para cada an̄o abarca datos desde agosto del an̄o previo hasta julio del año en curso

Fuente: CAPECO y BBVA Research

Figura 4. Venta de departamentos nuevos. (BBVA Research)

\subsection{Precio}

En el año 2018, el precio por metro cuadrado en Villa el Salvador según la Asociación de Desarrolladores Inmobiliarios del Perú (ADI) era de S/ 2625.29; sin embargo, en el 2019 asciende a S/ 2,700 en promedio." (Gestión). Los departamentos de 70 m2 tendrán un precio de S/ 186,000, y los de $75 \mathrm{~m} 2$ se ofertarán en S/ 202,500. 


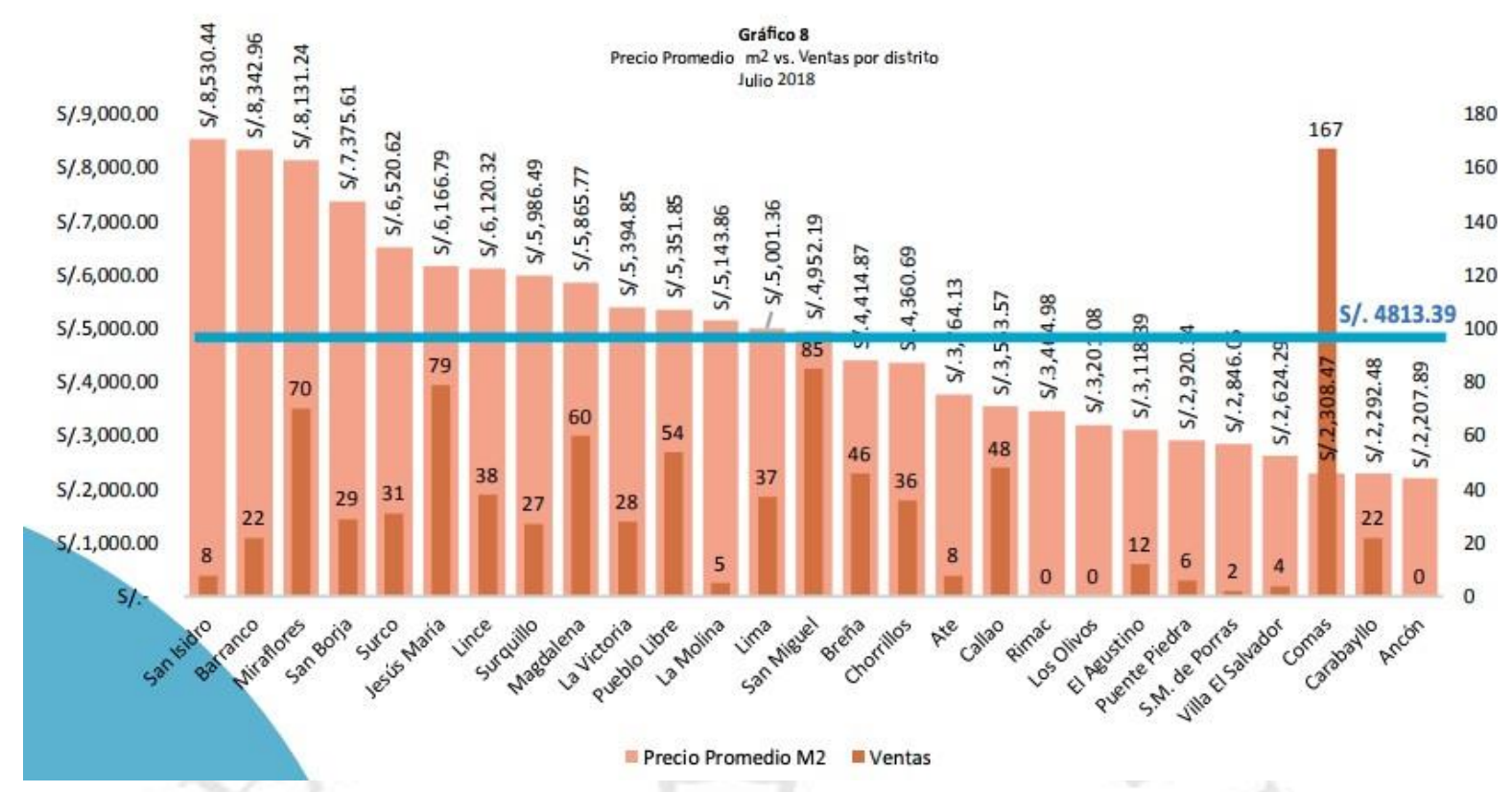

Figura 5. Precio promedio m2.Ventas por distrito ADI (2018)

\subsection{Producto}

Para promocionar la venta de departamentos de "La Villa del Atleta", necesitamos tener mapeado los niveles de producto del inmueble. 


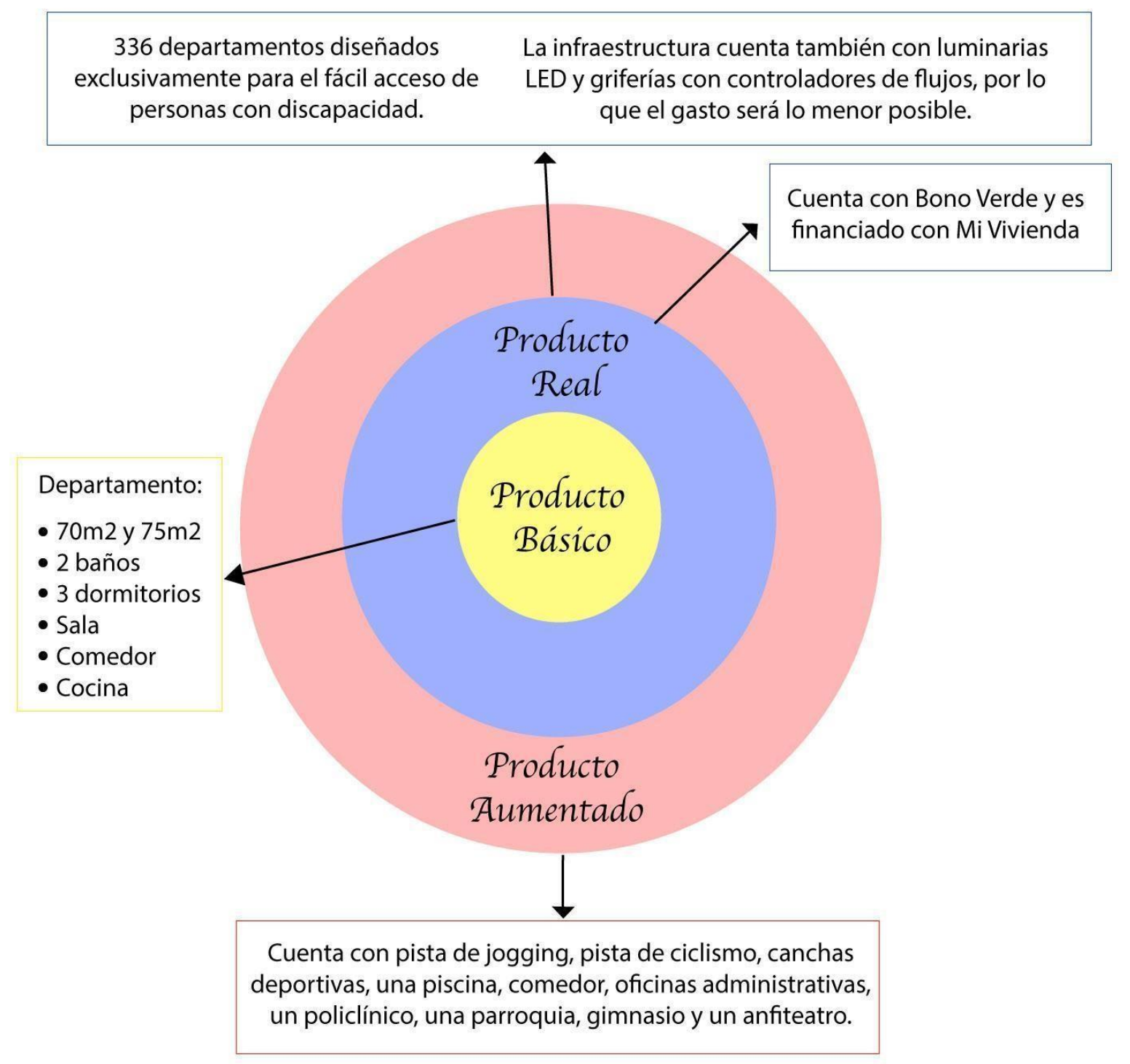

Elaboración propia

Figura 6. Niveles de producto. Elaboración propia

\section{PÚBLICO OBJETIVO}

Para identificarnos con nuestro público objetivo buscamos información secundaria y realizamos una investigación primaria con entrevistas a profundidad. Asimismo, desarrollamos un empathy map en donde resaltamos los principales insights de los millennials. 
Según el informe "Perfil del adulto joven peruano" (IPSOS, 2018), "Comprador en línea" (IPSOS, 2018), "Perfil del smartphonero" (IPSOS, 2018), "Hábitos, usos y actitudes hacia el internet"(IPSOS, 2018), "Bancarización del peruano. Bancos, Cajas y Financieras" (IPSOS, 2018), "Consumo de medios 2018. Consumo de medios de comunicación digitales y tradicionales" (IPSOS, 2018) encontramos información relevante de nuestro target.

\subsection{Perfil demográfico y familiar}

- En relación a la situación sentimental, los solteros sin pareja son la población más grande.

- Asimismo, el NSC C y D representa el $33 \%$ y $29 \%$ de la población respectivamente.

- La meta más importante para un adulto joven es tener un trabajo, casa propia y estudios.

- El 69\% de los adultos jóvenes aún viven con sus padres

- Tienen la intención de mudarse en los próximos 2 años en un 52\%.

\subsection{Perfil económico y financiero}

- La mayoría son colaboradores de alguna empresa en un 61\%, mientras que uno de cada cinco son trabajadores independientes.

-El ingreso mensual promedio de un adulto joven dependiente de una empresa es de $\mathrm{S} / 1300$.

-Los varones ganan un promedio de S/1500, mientras que las mujeres S/1000.

- Las remuneraciones quincenales y mensuales son la principal fuente de ingresos.

- $\quad 79 \%$ de los adultos jóvenes ahorra para comprar un departamento.

- $\quad$ El nivel de bancarización del adulto joven es de 39\% y son principalmente clientes de entidades bancarias.

- $\quad$ El bancarizado peruano principalmente pertenece al NSE C y es trabajador dependiente.

- Los jóvenes adultos de 25 a 39 años son los que más ahorran (42\%) 


\subsection{Entretenimiento y consumo de medios}

-El principal medio de entretenimiento es la televisión, más de la mitad ven algún programa para divertirse.

-Principalmente les gusta salir a comer en un $43 \%$, pasear en el parque $38 \%$, hacer ejercicios o deporte $37 \%$ e ir al cine en un $34 \%$.

- Solo tres de cada 10 lee el periódico con la misma frecuencia.

- 1 de cada 5 tienen una cuenta de Spotify

\subsection{Comportamiento tecnológico}

- El 85\% son digitales. Se conectan a internet en promedio 6 veces a la semana.

- Ell $44 \%$ de la población se conecta durante la tarde.

- 3 de cada 4 jóvenes adultos es miembro de una red social, siendo facebook la principal en un $76 \%$ y whatsapp en un $52 \%$.

- $63.8 \%$ de los millennials en Perú busca un inmueble por el canal online (Según Urbania)

\subsection{Compras}

- A pesar de ser digitales, el $77 \%$ no compra por internet.

- $59.3 \%$ de Millenialls tienen la disposición de comprar una vivienda a corto plazo

- Más del 50\% de acuerdo a su categoría han adquirido inmuebles de 3 habitaciones (53\% millennials) por lo que se deduce que el peruano busca estabilidad y funcionalidad familiar según Urbania

\subsection{Encuestas}

Se realizaron 100 encuestas con el objetivo de conocer las percepciones de nuestro público objetivo y validar sus preferencias respecto a los departamentos de Villa Panamericana.

- En cuanto a “¿Cuál sería tu principal motivación para comprar un departamento?" Los resultados fueron los siguientes: 


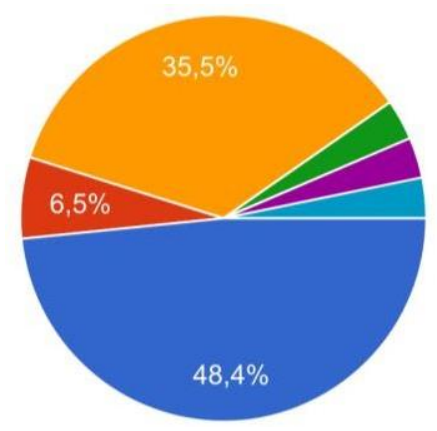

Independencia

Éxito

Realización personal

Negocio

Formar una familia

Familia

Figura 7. ¿Cuál sería tu principal motivación para comprar un departamento?

Elaboración propia

La mayoría de encuestados expresaron que el ser independientes es su principal motivación para realizar la compra de un departamento. Seguidamente de querer realizarse personalmente mientras que un pequeño porcentaje por lograr sentirse exitosos.

Por otro lado, recordemos que cada vez más las personas se independizan a una menor edad e incluso las financieras están brindando más facilidades a los créditos lo que repercuta en que el mercado apunte hacia un público joven adulto.

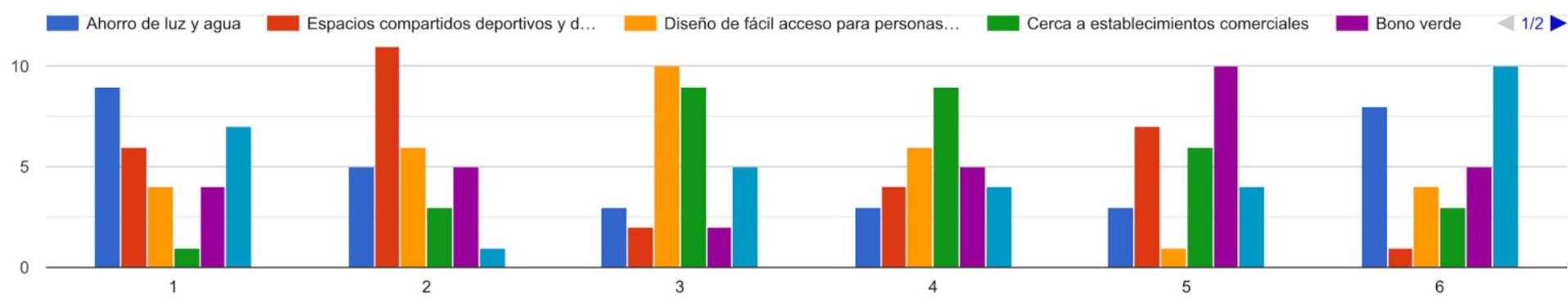

Figura 8. Enumera en orden lo que considerarías importante al adquirir un departamento sabiendo que 1 (menos importante )y 6 (más importante). Elaboración propia

Los encuestados reflejan que el beneficio que más resaltan es el ahorro de luz y agua. En segundo lugar, encontramos al bono verde que es una gran facilidad de financiamiento para muchos y en tercer lugar que los departamentos sean inclusivos, es decir que presenten una infraestructura accesible para personas que tengan diferentes tipos de discapacidades. Por otro lado, un aspecto menos relevante que estén situadas cerca a centros comerciales. Todo esto nos ayuda a seleccionar los atributos o beneficios que nuestros entrevistados más destacan al momento de evaluar un departamento. 
Saliendo del terreno de los beneficios, se les consultó cómo calificaban estos departamentos.

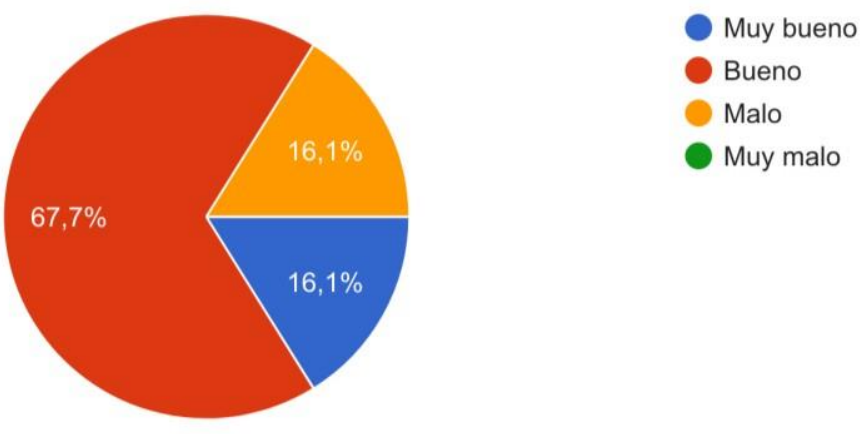

Figura 9 ¿Cómo calificarías a estos departamentos si se encuentran en Villa El Salvador? Elaboración propia

La mayoría de los esntrevistados consideran beneficioso y conveniente que se encuentren estos departamentos en el distrito de Villa El Salvador aunque hay un pequeño porcentaje que considera que la zona es un poco insegura lo que les hace dudar la ubicación elegida para su construcción.

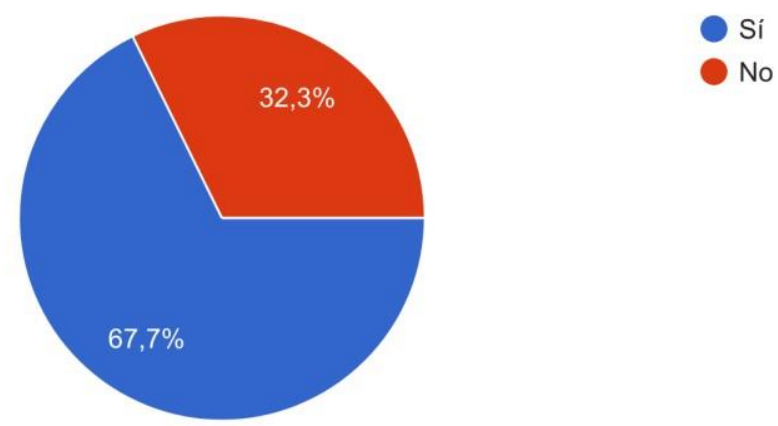

Figura 10. Recordando que en la "Villa del Atleta” viven los campeones de los panamericanos, ¿te gustaría vivir en esta villa? Elaboración propia

Otro factor importante que consideramos al realizar las encuestas es saber si nuestro público objetivo valoraba que en estos departamentos, nuestros campeones de los Panamericanos habían obtenido un departamento. Incluso muchos comentaban se sería interesante tenerlos como sus vecinos al ser considerados un buen ejemplo para los niños y adolescentes, además de ser de orgullo para el país. 


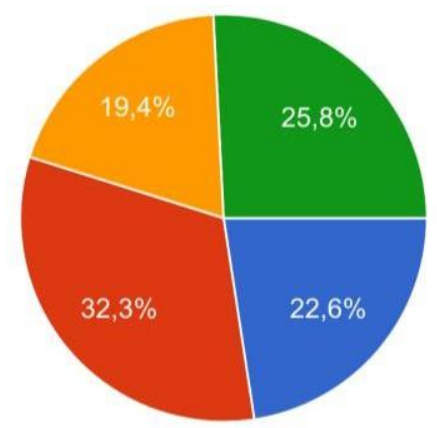

Villa de Campeones

Villa Panamericanos

Condominio de Campeones

Condominio Panamericanos

Figura 11 ¿ Cómo te gustaría que se llame este proyecto? Elaboración propia

Según las opiniones de los encuestados prefieren que el nombre esté relacionado al concepto de Panamericanos. Todo ello, nos ayudó a decidir que se continuara con el nombre inicial y no haya algún cambio o variación en el nombre. Además, porque el concepto de Panamericanos ya está fijado en la mente de todo las personas y de todas las edades al haber tenido una gran aceptación no solo en el país sino también al mundo entero.

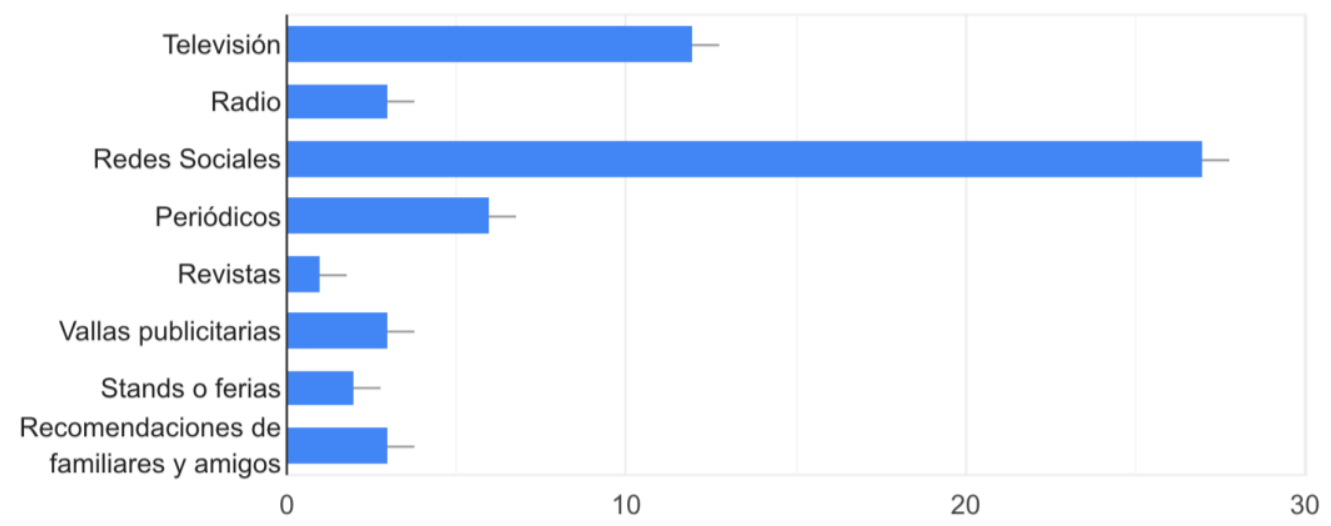

Figura 12 ¿ De qué manera prefieres enterarte de las ventas de estos departamentos? Elaboración propia

Finalmente decidimos preguntar los medios por los cuales a ellos les gustaría enterarse siendo las redes sociales el medio más escogido seguidamente de la televisión, los periódicos y las vallas publicitarias. Asimismo, con menor relevancia está la radio, los stands y las revistas inmobiliarias.

\subsection{Buyer persona}


Con el objetivo de sintetizar los hallazgos mencionados anteriormente, se elaboró un buyer persona llamado Pepe luchador quien resume el perfil de nuestro público y de qué forma necesitamos empatizar con él.

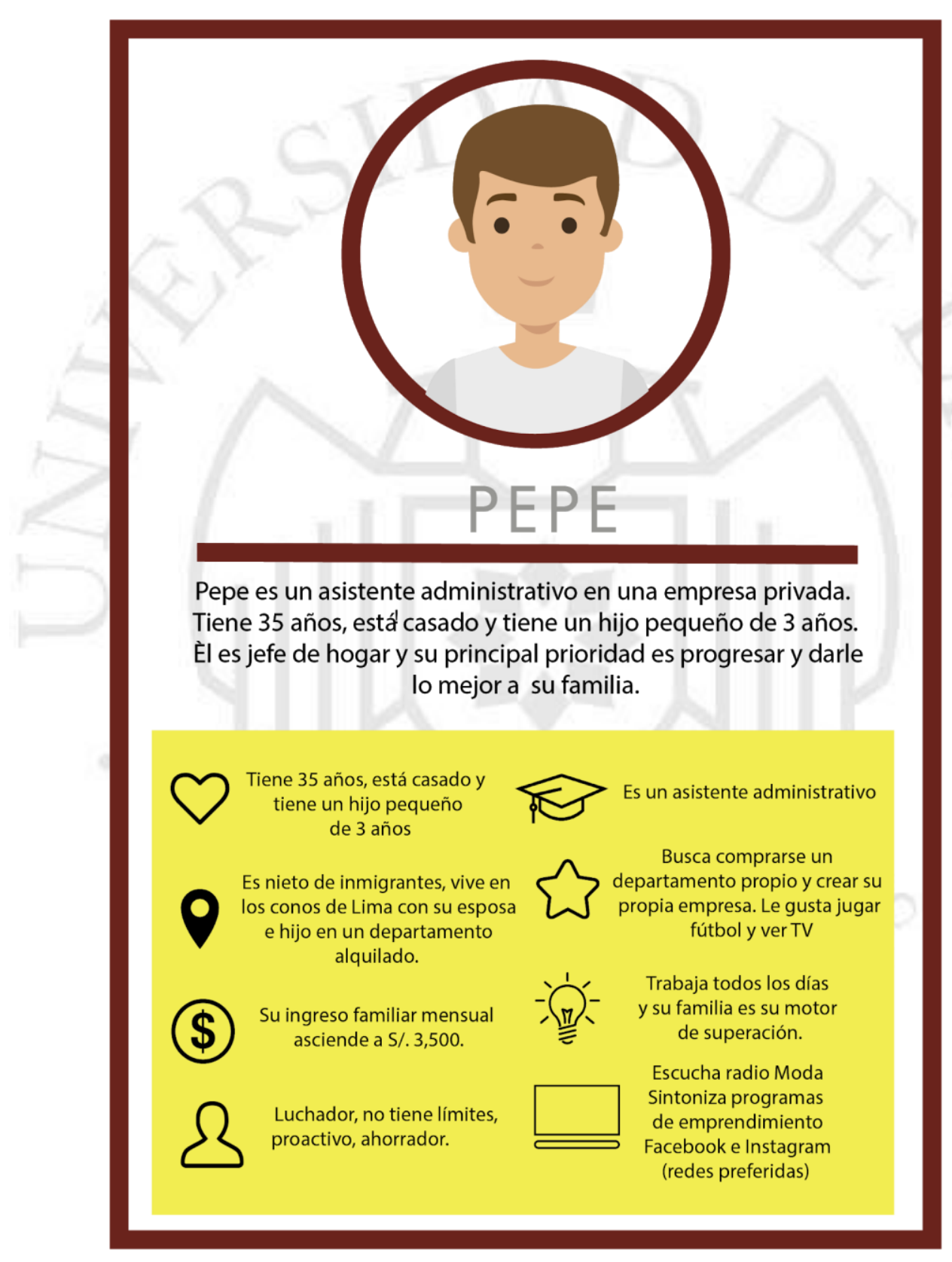

Figura 13 Buyer persona Elaboración propia 


\section{La Marca}

\subsection{Posicionamiento BESCO}

\begin{tabular}{|c|c|c|}
\hline $\begin{array}{l}\text { Herencia: } \\
\text { BESCO se crea en } 1998 \text {, } \\
\text { empresa peruana con más de } \\
19 \text { años en el mercado, la cual } \\
\text { se ha consolidado con una } \\
\text { imagen emprendedora, } \\
\text { confiable y exitosa; dedicada } \\
\text { a construir bienestar para } \\
\text { todos sus clientes. }\end{array}$ & 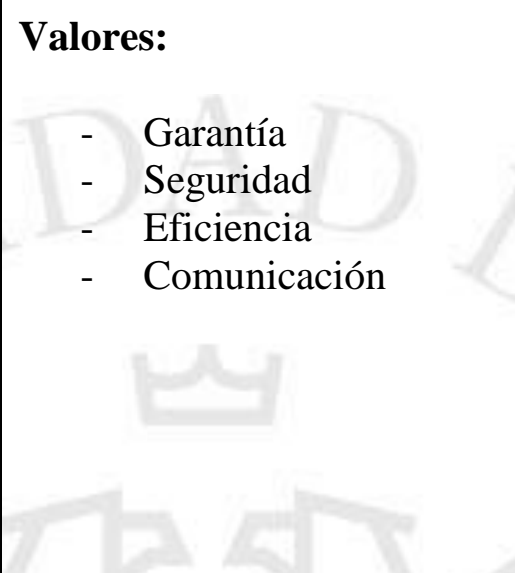 & 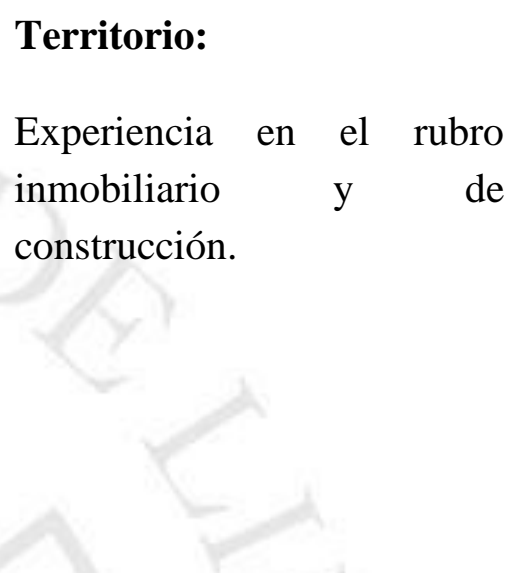 \\
\hline & & \\
\hline $\begin{array}{l}\text { Ocasiones y usuarios: } \\
\text { Usuarios: Jóvenes adultos } \\
\text { de } 25 \text { a } 39 \text { años del NSE C y } \\
\text { D de espìritu emprendedor } \\
\text { que trabajan diariamente } \\
\text { para superarse y tener un } \\
\text { mejor estilo de vida junto a } \\
\text { su familia. }\end{array}$ & $\begin{array}{l}\text { Personalidad: } \\
\text { Pepe es un peruano luchador } \\
\text { y su principal motivación es } \\
\text { darle lo mejor a su familia. } \\
\text { Desea comprarse un terreno } \\
\text { propio o departamento }\end{array}$ & $\begin{array}{l}\text { Íconos y propiedades de } \\
\text { marca: } \\
\text { Colores } \\
\text { Tipografía } \\
\text { Presentación }\end{array}$ \\
\hline
\end{tabular}

Tabla 7. Esencia de Marca. Elaboración propia 


\subsection{Misión y visión de marca de BESCO Emprendedor}

Misión: Ofrecer al peruano emprendedor departamentos ahorrativos, eco amigables e inclusivos.

Visión: Ser líderes en el mercado inmobiliario

\subsection{Posicionamiento de BESCO Emprendedor}

Posicionarnos en el mercado inmobiliario de departamentos ahorrativos, eco amigables e inclusivos orientados al público emprendedor.

\subsection{Arquitectura de marca: Principios organizadores de Besco Emprendedor}

- Precio: Económico

- Mindset: Ser bien peruano, emprendedor, espíritu ganador.

Estos organizadores fueron elegidos al ser dirigido a un público del NSE C y D, además son departamentos con precios económicos en relación con la competencia. Asimismo, lo segmentamos por mindsets ya que nos estamos dirigiendo a los millennials peruanos de espíritu emprendedor.

\subsection{Promesa - Villa Panamericanos}

Villa Panamericanos es un condominio donde viven los campeones de los Panamericanos. Estos departamentos son financiados con crédito Mi Vivienda, son inclusivos y ahorrativos en agua y energía.

\subsection{Ventaja diferencial - Villa Panamericanos}

Entregamos departamentos para peruanos emprendedores, los cuales son financiados con crédito Mi Vivienda, son eco amigables, ahorrativos e inclusivos.

\subsection{Reason why}

- Aquí viven los peruanos ganadores de los juegos panamericanos

- Eco amigable y ahorrativo

- La infraestructura cuenta con luminarias LED y griferías con controladores de flujos, por lo que el gasto en agua y energía será lo

- Inclusivo menor posible.

- "Villa Panamericanos" incluye 336 departamentos diseñados exclusivamente para el fácil acceso de personas con discapacidad, además, algunas de las zonas cuentan con el sistema de lectura braille.

- ¡Más beneficios!

- Los departamentos tienen 3 cuartos, 2 baños, sala, comedor y cocina y son de 70 y $75 \mathrm{~m} 2$.

- Tendrás espacios deportivos compartidos: Pista de jogging, pista de ciclismo, canchas deportivas, piscina y gimnasio.

- "La Villa Panamericanos" también cuenta con policlínico, oficinas administrativas, parroquia y anfiteatro. 
- Pronta construcción de establecimientos comerciales: "El proyecto original contemplaba la construcción de más edificios, sin embargo, se redujo y se liberó terreno que quedará libre para el desarrollo de comercio, en base a planes urbanísticos." (Gestión).

- Villa Panamericanos está respaldada por la empresa BESCO, la cual ha realizado grandes proyectos como los Prados de Chaclacayo (ambientes sociales compartidos, deportivos y de entretenimiento), Condominio Central 10.5,etc.

\subsection{Tono de Comunicación}

La comunicación de "Villa Panamericanos" se caracteriza por ser cercano e informal y así empatizar con la audiencia. Por ello, haremos uso de influencers (mayormente utilizados al dirigirse hacia el target millenial) quienes personifican el mensaje que nuestra marca BESCO Emprendedor desea transmitir. Asimismo, es informativo y demostrativo al explicar los beneficios del condominio para generar preferencia por el cliente.

\section{IMAGEN DE MARCA - BESCO Emprendedor}

\subsection{Logo}

Se eligió el nombre emprendedor, palabra que describe una de las características del progresista peruano, principalmente por su carácter luchador y de querer superar sus propios límites.

Por otro lado, el lanzamiento de esta nueva línea de negocio inicia en el contexto de los campeones peruanos de los Panamericanos y Parapanamericanos 2019.

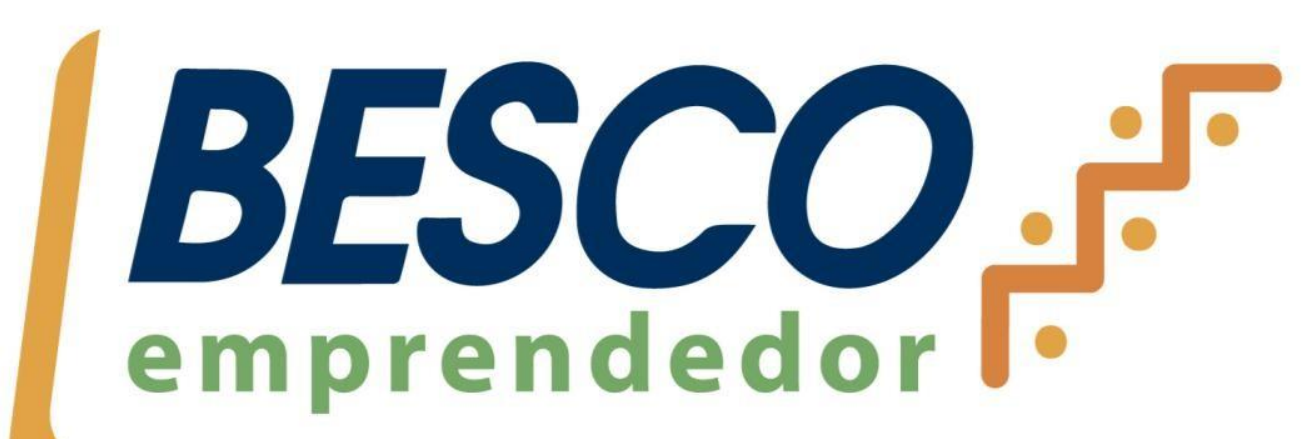




\subsection{Colores}

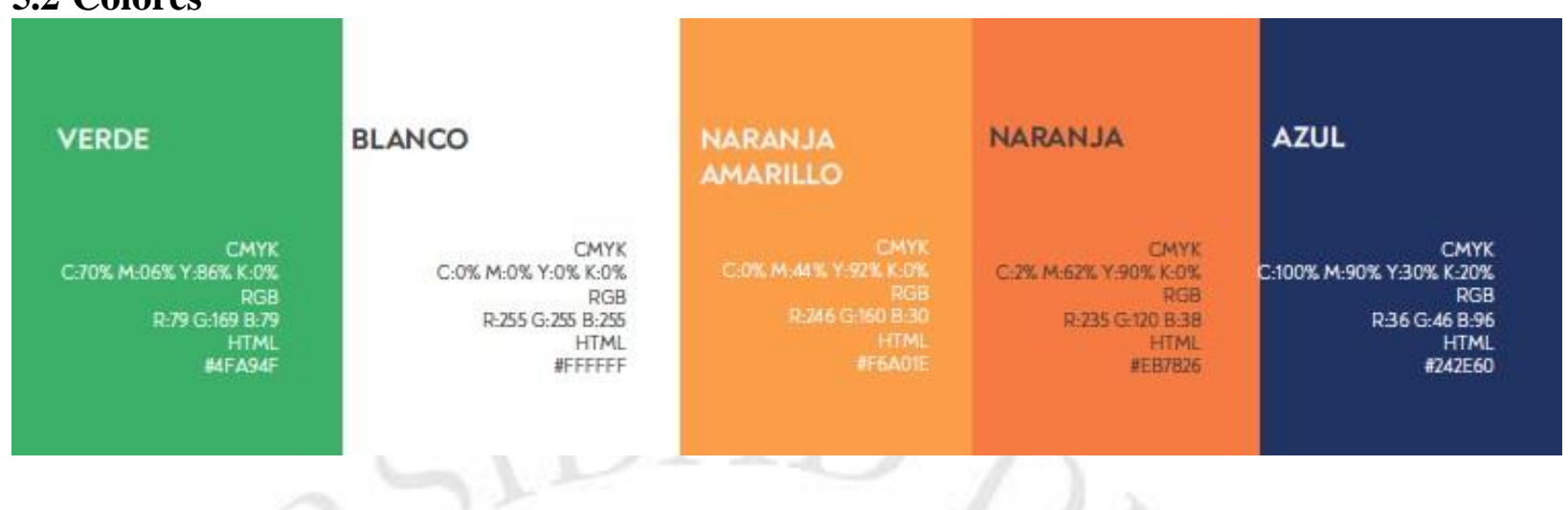

\subsection{Manual de Marca}

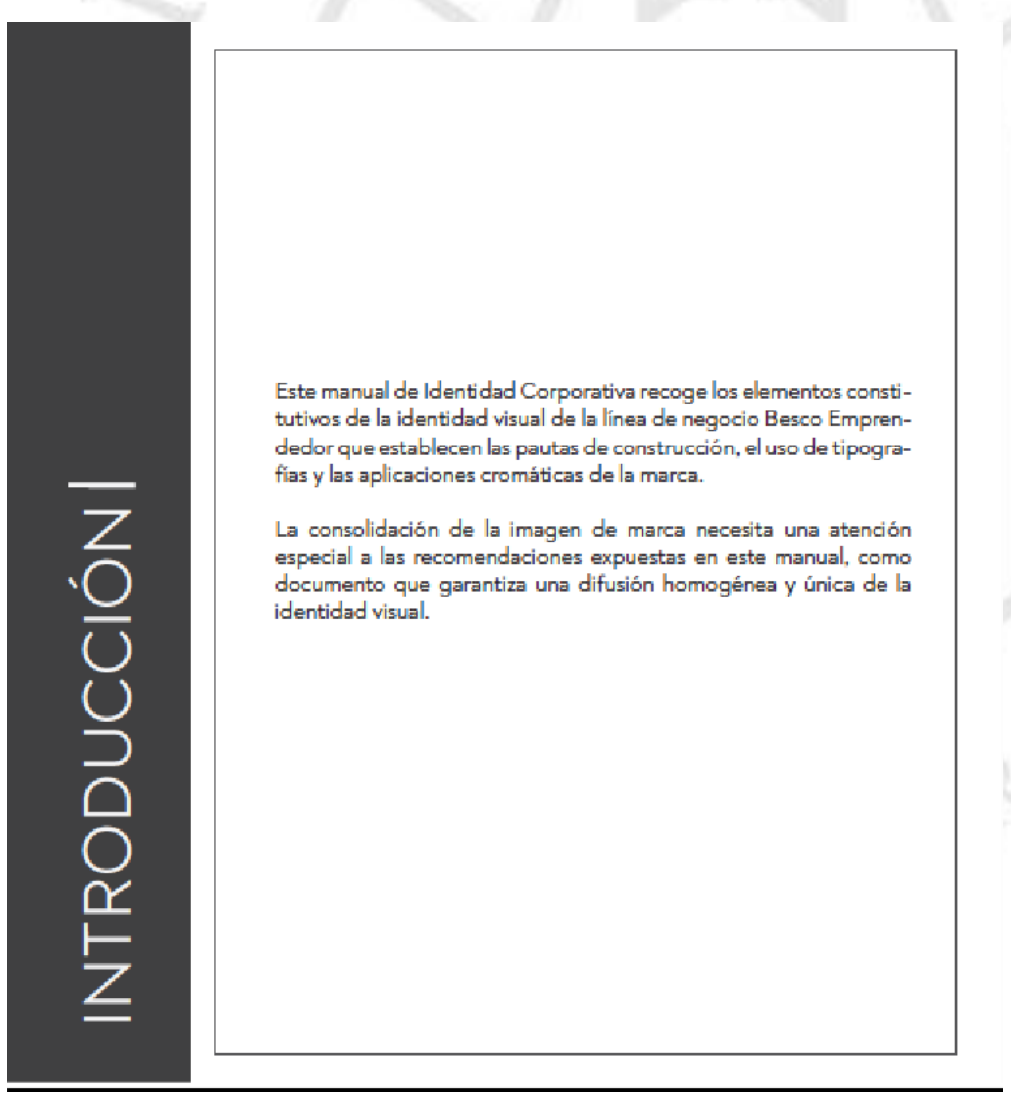




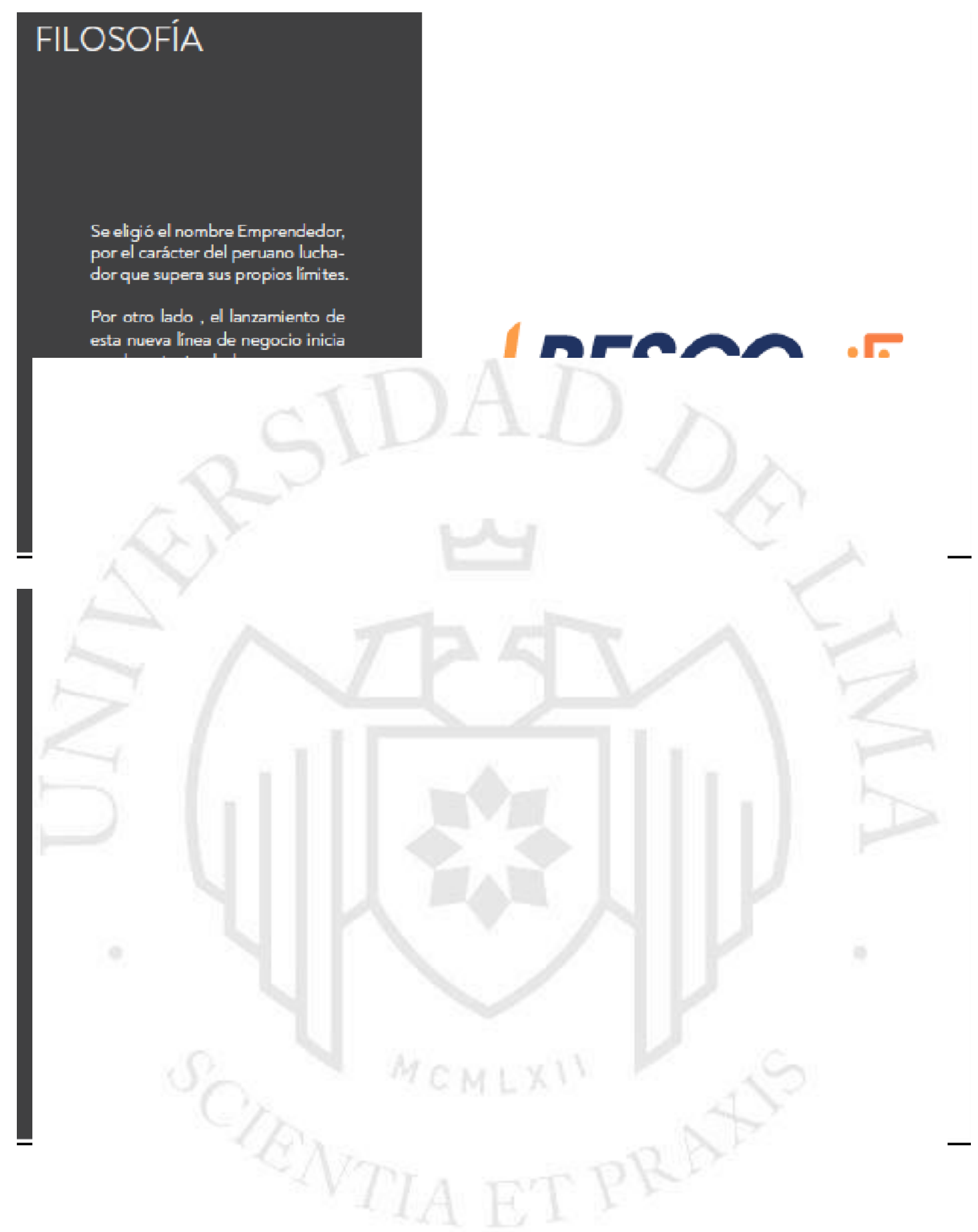




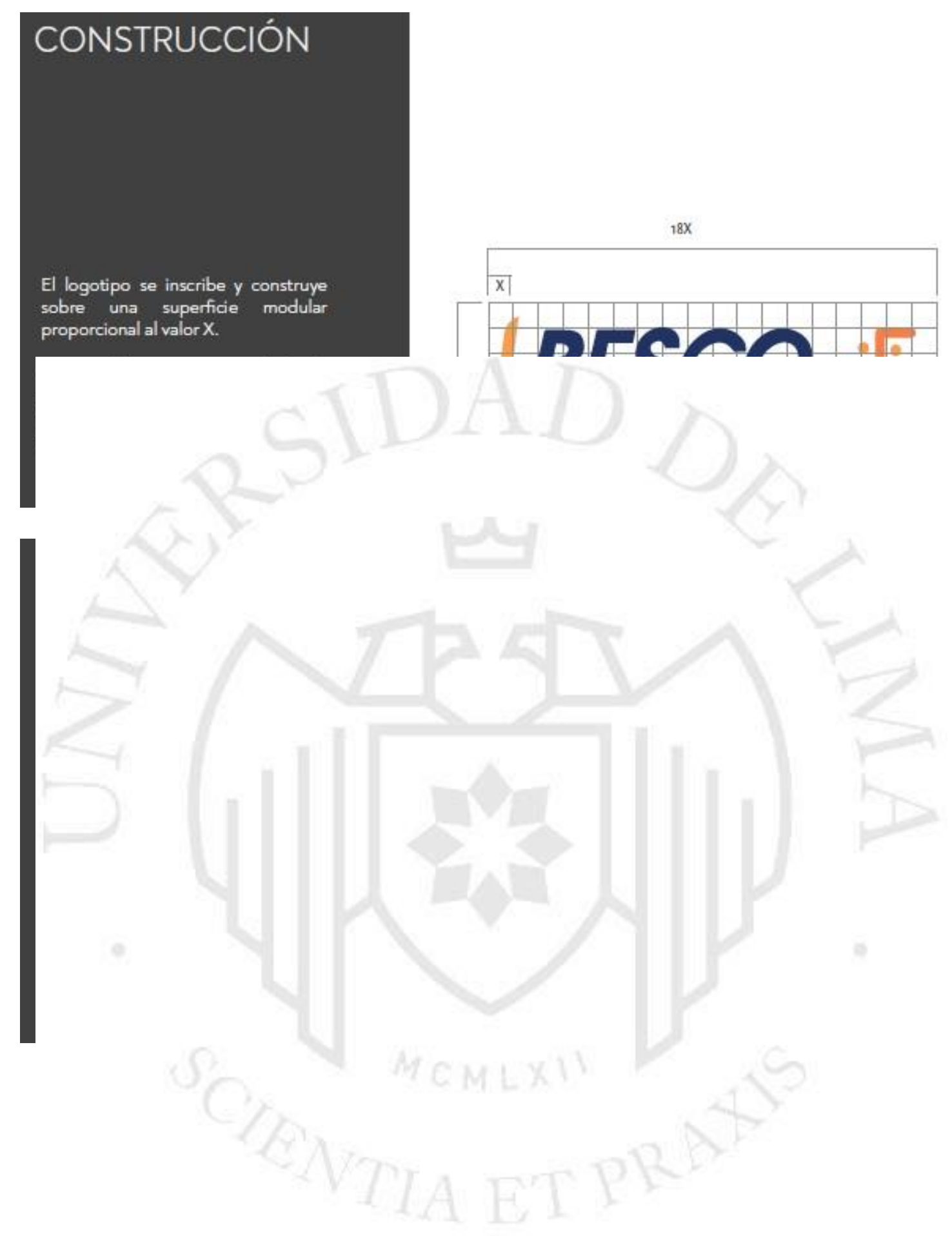




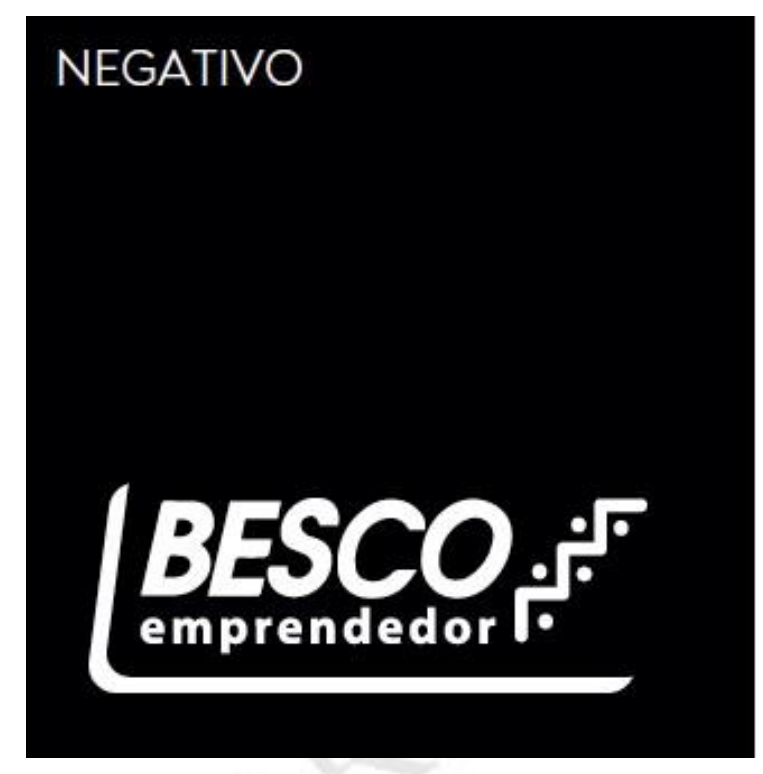

\section{POSITIVO}

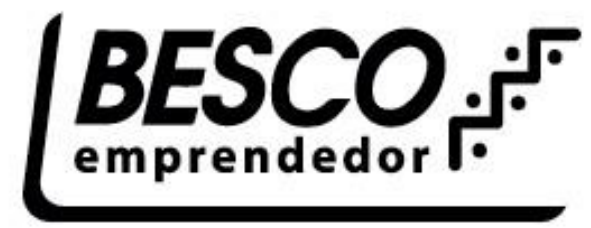

\section{TAMAÑOS}

MINIMOS DE REPRODUCCIÓN

OFFSET/SERIGRAFÍA

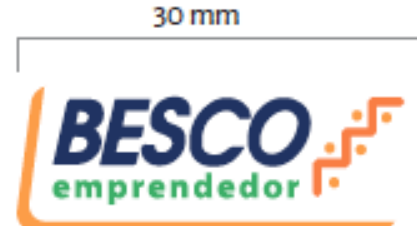

Desde un tamaño máximo ilimitado, se establecen unos tamaños mínimos de reproducción impresa y digital.

\section{Digital}

WEB/VIDEO

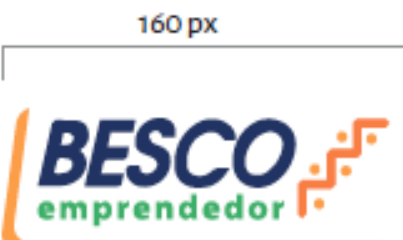

\section{CAMPAÑ}

\subsection{OBJETIVOS}

6.1.1 OBJETIVO DE MARKETING:

- Vender 1,096 departamentos desde enero a junio del 2020. 


\subsubsection{OBJETIVOS DE COMUNICACIÓN:}

\section{Objetivo primario}

- Comunicar a los peruanos de espíritu emprendedor el proyecto Villa Panamericanos y sus características.

\section{Objetivo secundario}

- Comunicar al target acerca de las modalidades de financiamiento a través del programa Mivivienda.

Hemos integrado el primer y segundo objetivo ya que toda comunicación con el cliente debe generar una acción.

\subsection{Estrategia creativa}

\subsubsection{Concepto}

Concepto: "Vive como campeón"

El concepto alude a que cualquier peruano emprendedor que compre estos departamentos vivirá como un verdadero campeón. Los campeones son luchadores constantes en búsqueda de superación, son disciplinados y se sacrifican para llegar a la meta, al igual que un emprendedor. En este caso, los compradores de Villa Panamericanos también serán recompensados como ganadores al adquirir beneficios de ahorro, inclusividad y ser parte de la gran familia de campeones.

\subsubsection{Idea}

Idea: ¿Cómo vive un campeón?

Para aterrizar este concepto contaremos cómo es el día a día de un campeón en la Villa Panamericanos.

- Ahorra luz y agua.

- Tiene espacios inclusivos

- Se ejercita todas las mañanas: Trota en las mañanas.

- En las tardes va al gimnasio. 
- Los fines de semana se relaja en la piscina

- Juega futbol en las canchas deportivas con otros campeones.

- Después de una lesión, va al policlínico a atenderse.

\subsubsection{Pilares de Comunicación}

\begin{tabular}{|c|c|c|}
\hline MARCA & $\begin{array}{l}\text { PRODUCTO - } \\
\text { SERVICIO }\end{array}$ & BENEFICIOS EXTRAS \\
\hline $\begin{array}{l}\text { Transmitir la misión y } \\
\text { visión de Besco } \\
\text { Emprendedor a nuestro } \\
\text { target a través del } \\
\text { proyecto Villa } \\
\text { Panamericanos. }\end{array}$ & $\begin{array}{l}\text { Características intrínseca } \\
\text { del bien inmueble. }\end{array}$ & $\begin{array}{l}\text { Elementos adicionales que } \\
\text { son un plus a nuestro } \\
\text { producto - servicio. }\end{array}$ \\
\hline \multicolumn{3}{|c|}{ SUB EJES } \\
\hline $\begin{array}{l}\text { - Marca Besco } \\
\text { Emprendedor } \\
\text { - Campaña } \\
\text { "Vive como } \\
\text { campeón" }\end{array}$ & $\begin{array}{ll}\text { - } & \text { Mi Vivienda } \\
\text { - } & \text { Bono Verde } \\
\text { - } & \text { Eco amigable } \\
\text { - } & \text { Ahorrativo } \\
\text { - } & \text { Inclusivo }\end{array}$ & $\begin{array}{ll}\text { - } & \text { Pista de jogging } \\
\text { - } & \text { Pista de ciclismo } \\
\text { - } & \text { Gimnasio } \\
\text { - } & \text { Policlínico } \\
\text { - } & \text { Anfiteatro } \\
\text { - } & \text { Entre otros }\end{array}$ \\
\hline
\end{tabular}

Tabla 8.Pilares de Comunicación. Elaboración propia

\subsection{Estrategia de Medios}

La campaña Villa Panamericanos iniciará el 21 de Diciembre del 2019 y tendrá fin el 31 de Marzo del 2020.

\begin{tabular}{|c|l|}
\hline ETAPA & \multicolumn{1}{|c|}{ LANZAMIENTO } \\
\hline OBJETIVO & $\begin{array}{l}\text { Generar awareness del } \\
\text { producto y concepto de } \\
\text { campaña }\end{array}$ \\
\hline DESCRIPCIÓN & $\begin{array}{l}\text { Realizaremos un } \\
\text { storytelling sobre el } \\
\text { concepto de la campaña y } \\
\text { los beneficios del }\end{array}$ \\
\hline
\end{tabular}




\begin{tabular}{|l|l|}
\hline & producto - servicio. \\
\hline MEDIOS & Digital \\
& ATL \\
& Punto de Venta \\
\hline
\end{tabular}

Tabla 9.Estrategia de Medios. Elaboración propia

En la campaña de lanzamiento generamos conocimiento de los atributos de Villa Panamericana.

\section{Ecosistema de Medios}

\section{Medios ATL \\ o Radio \\ o $\mathrm{OOH}$ \\ Digital \\ o Facebook \\ o Instagram \\ o Youtube \\ o Influenciadores}

BTL

Punto de venta

El mensaje se anunciará en dos medios importantes de acuerdo a las preferencias del target: Medios tradicionales y digitales 

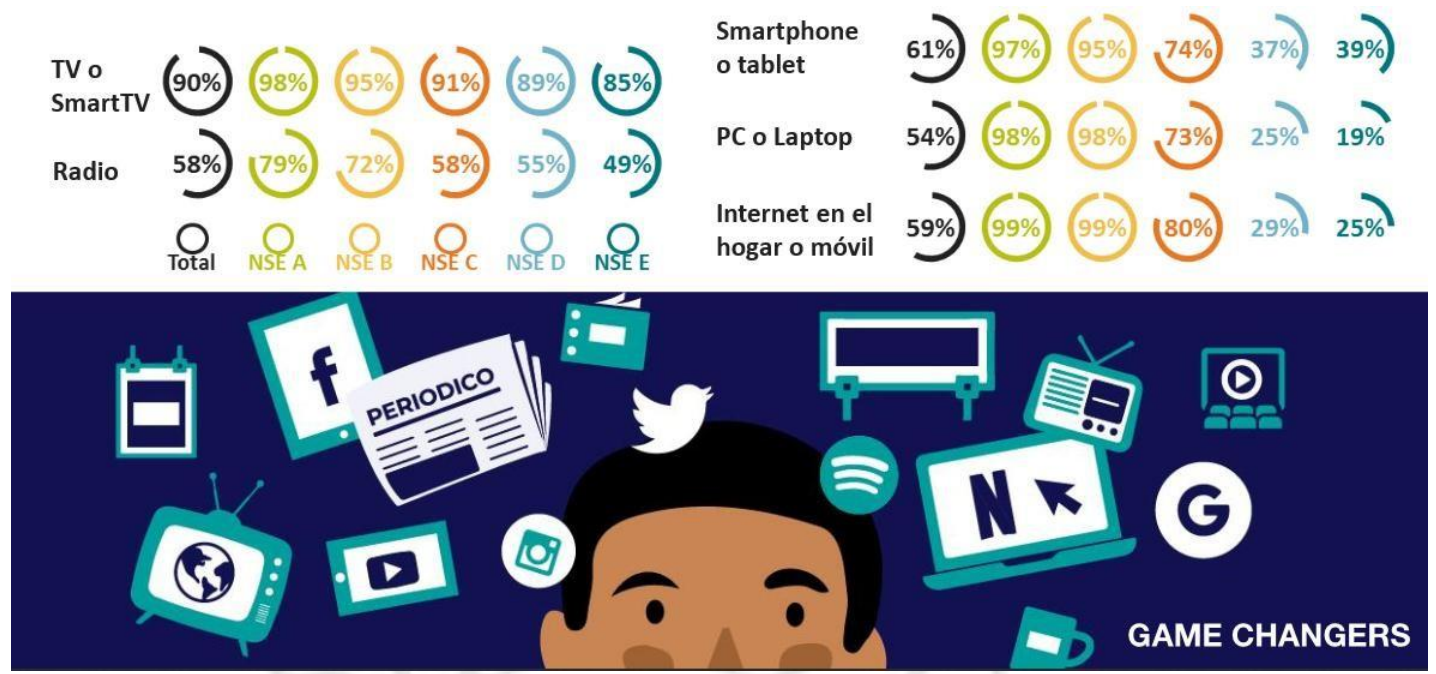

Figura 14 Medios tradicionales y digitales.IPSOS (2018)

Por otro lado destacamos que los medios tradicionales tienen mayor consumo por nuestra target en un 54\% del NSE C y un 67\% del NSE D

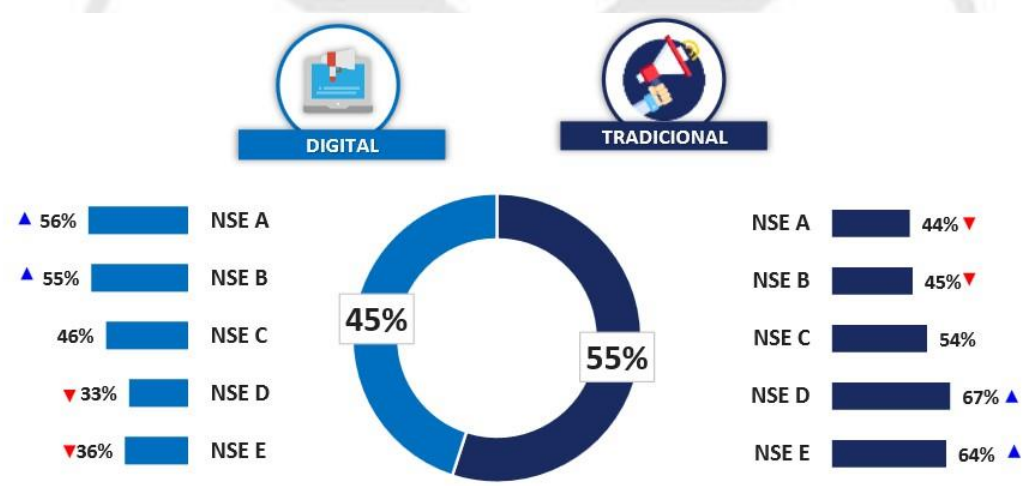

"Poco más de la mitad del tiempo de consumo se da en los medios tradicionales"

Figura 15 Consumo de Medios tradicionales y digitales. IPSOS (2018)

\section{ATL}

Priorizaremos los anuncios en TV. "Los mensajes de marca que anuncian en .. cine, televisión abierta... logran captar la atención de más de $30 \%$ de consumidores" (Ipsos) https://www.ipsos.com/es-pe/publicidad-en-medios$\underline{\text { tradicionales-todavia-capta-mayor-atencion-que-en-los-digitales }}$ 


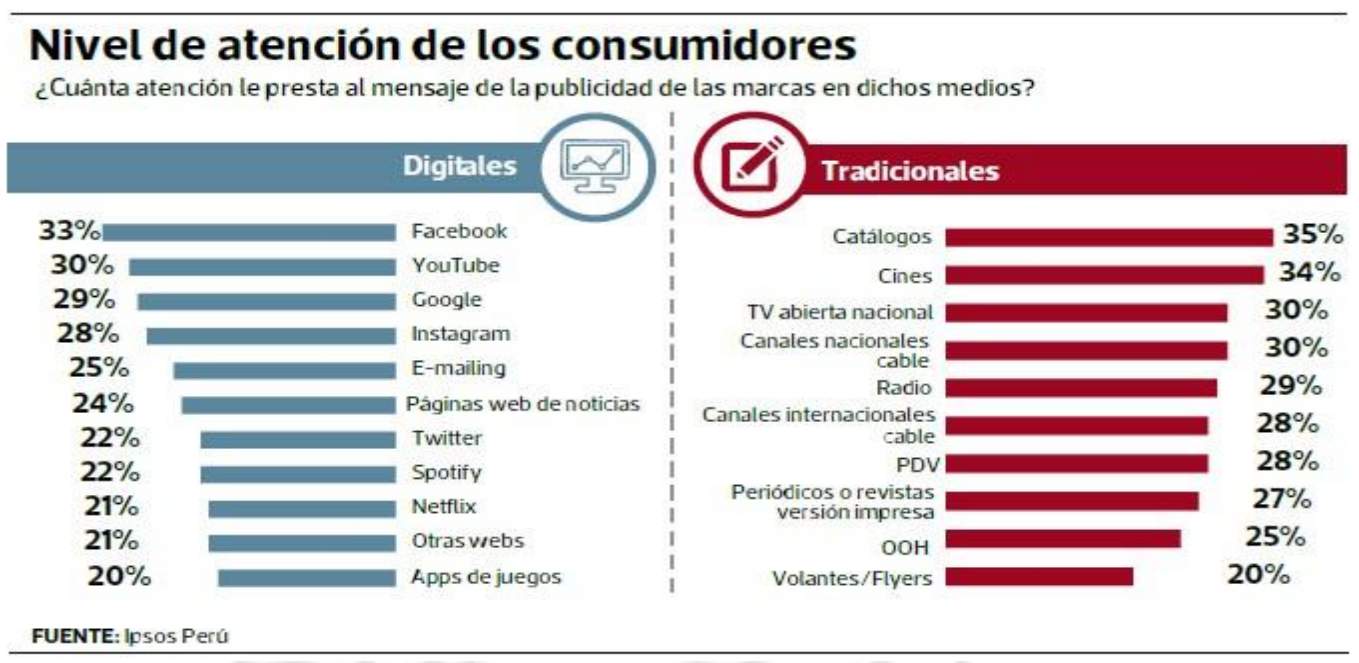

Figura 16 Nivel de atención de consumidores. ARELLANO (2018)

\section{TELEVISIÓN}

En promedio, nuestro target en TV abierta consume 9:49 horas por semana en NSE C y 10:24 horas en el NSE D, asimismo en cable nacional consume consume 6.24 horas por semana en NSE C y 2:36 horas en NSE D.

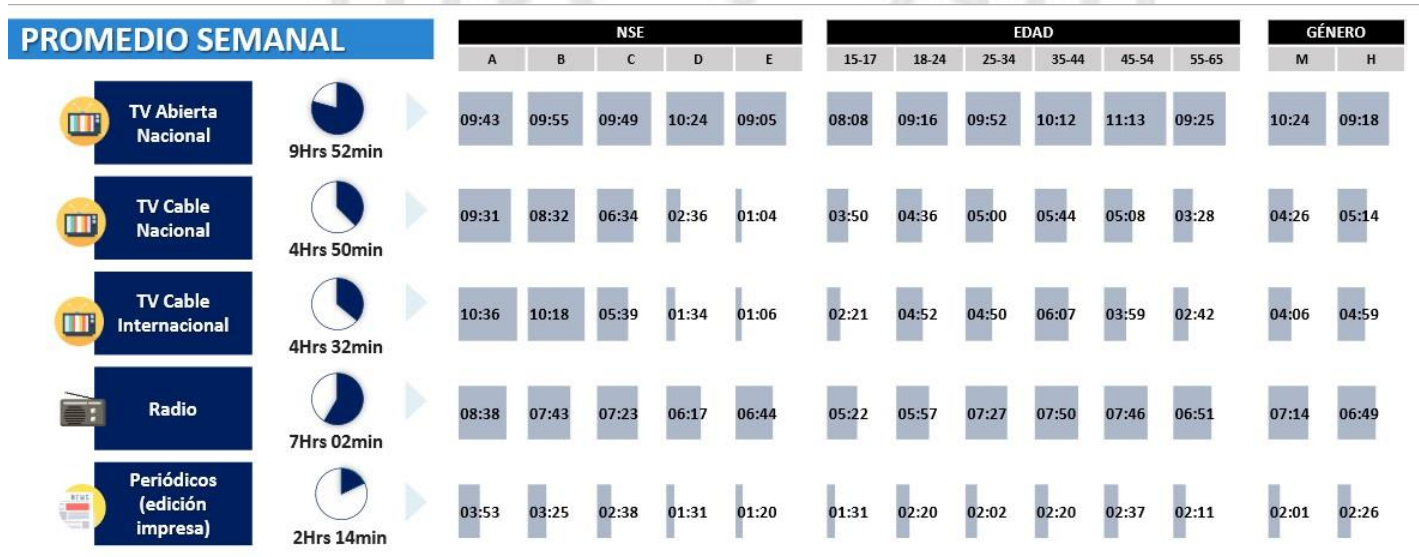

Figura 17.Promedio Semanal Medios tradicionales IPSOS(2018) 
Asimismo, el NSE C consumo varias veces al día TV abierta en un 33\% mientras que el NSE D en un 27\%. Además, los millennials de 25 - 34 años consumen Tv abierta en $25 \%$.

\begin{tabular}{|c|c|c|c|c|c|c|c|}
\hline \multicolumn{8}{|c|}{ PERFIL DE CONSUMIDORES } \\
\hline & & TOTAL & Varias veces al día & 1 vez al día & $\begin{array}{l}\text { Varias veces por } \\
\text { semana }\end{array}$ & $\begin{array}{c}1 \text { vez por semana o } \\
\text { menos }\end{array}$ & Nunca \\
\hline \multirow{5}{*}{ NSE } & A & $3 \%$ & $3 \%$ & $3 \%$ & $3 \%$ & $2 \%$ & $1 \%$ \\
\hline & B & $16 \%$ & $22 \% \triangle$ & $12 \% \mathrm{~V}$ & $15 \%$ & $17 \%$ & $15 \%$ \\
\hline & c & $34 \%$ & $33 \%$ & $31 \%$ & $45 \%$ & $36 \%$ & $27 \% \quad V$ \\
\hline & D & $29 \%$ & $27 \%$ & $34 \%$ & $22 \%$ & $31 \%$ & $23 \%$ \\
\hline & E & $18 \%$ & $15 \% \mathrm{~V}$ & $20 \% \nabla$ & $15 \% \nabla$ & $14 \% \mathrm{~V}$ & $34 \%$ \\
\hline \multirow{6}{*}{ EDAD } & $15-17$ & $8 \%$ & $8 \%$ & $5 \%$ & $10 \%$ & $10 \%$ & $10 \%$ \\
\hline & $18-24$ & $18 \%$ & $\frac{070}{18 \%}$ & $16 \%$ & $22 \%$ & $23 \% \Delta$ & $18 \%$ \\
\hline & $25-34$ & $25 \%$ & $25 \%$ & $21 \% \mathrm{~V}$ & $30 \%$ & $31 \%-\Delta$ & $18 \% \mathrm{~V}$ \\
\hline & $35-44$ & $21 \%$ & $23 \%$ & $22 \%$ & $19 \%$ & $14 \%$ & $23 \%$ \\
\hline & $\begin{array}{l}35-44 \\
45-54\end{array}$ & $16 \%$ & $16 \%$ & $22 \%$ & $6 \% \mathrm{~V}$ & $13 \%$ & $16 \%$ \\
\hline & $55-65$ & $12 \%$ & $10 \%$ & $14 \%$ & $13 \%$ & $9 \%$ & $15 \%$ \\
\hline \multirow{2}{*}{ SEXO } & Hombres & $50 \%$ & $45 \%$ & $51 \%$ & $49 \%$ & $55 \%$ & $58 \%$ \\
\hline & Mujeres & $50 \%$ & $55 \%$ & $49 \%$ & $51 \%$ & $45 \%$ & $42 \%$ \\
\hline \multirow{6}{*}{ REGIÓN } & Lima & $42 \%$ & $45 \%$ & & $41 \%$ & $38 \%$ & $29 \% \quad V$ \\
\hline & Costa Norte & $17 \%$ & ${ }_{19 \%}^{40 \%} \Delta$ & $17 \%$ & & $19 \% \triangle$ & $7 \% \nabla$ \\
\hline & Costa Centro y Sur & $9 \%$ & $6 \% \mathrm{~V}$ & $79 \%$ & $16 \% \Delta$ & $5 \% \nabla$ & $17 \% \Delta$ \\
\hline & Sierra Centro y Norte & $10 \%$ & $9 \%$ & $8 \% \mathrm{~V}$ & $8 \%$ & $13 \%$ & $18 \% \triangle$ \\
\hline & Sierra Sur & $12 \%$ & $14 \%$ & $12 \%$ & $9 \%$ & $15 \%$ & $10 \%$ \\
\hline & Oriente & $10 \%$ & $7 \% 7$ & $12 \%$ & $9 \%$ & $10 \%$ & $19 \% \Delta$ \\
\hline
\end{tabular}

Figura 18. Perfil del consumidor. IPSOS(2018)

Priorizaremos nuestro anuncio en America TV por ser un canal líder, el cual se identifican los millennials.

\section{ATRIBUTOS DE CANALES DE TV NACIONAL - MENCIONES ABSOLUTAS}

\begin{tabular}{|c|c|c|c|c|c|c|c|c|c|c|c|}
\hline & \# & : & N & C & ivperu & M & RPO & CAPIAL: & $n_{\text {Depo }}$ & $m_{\text {Plus }}$ & Dillax \\
\hline & América & Latina & ATV & anamerican & TV Perú & Canal $\mathbf{N}$ & RPP TV & Capital IV & \begin{tabular}{|l|} 
Movistar \\
Deportes
\end{tabular} & $\begin{array}{c}\text { Movistar } \\
\text { Plus }\end{array}$ & willax TV \\
\hline Tiene los mejores periodistas & $41 \%$ & $25 \%$ & $18 \%$ & $8 \%$ & $12 \%$ & $9 \%$ & $18 \%$ & $4 \%$ & $3 \%$ & $1 \%$ & $2 \%$ \\
\hline Tiene buenos noticieros/ programas periodísticos & $40 \%$ & $26 \%$ & $19 \%$ & $13 \%$ & $18 \%$ & $10 \%$ & $23 \%$ & $4 \%$ & $2 \%$ & $1 \%$ & $2 \%$ \\
\hline Informan de manera objetiva, veraz e imparcial & 33\% & $23 \%$ & $16 \%$ & $11 \%$ & $15 \%$ & $8 \%$ & $20 \%$ & $4 \%$ & $3 \%$ & $2 \%$ & $1 \%$ \\
\hline Tiene los mejores programas de entretenimiento & $46 \%$ & $32 \%$ & $16 \%$ & $8 \%$ & $11 \%$ & $2 \%$ & $2 \%$ & $2 \%$ & $4 \%$ & $3 \%$ & $5 \%$ \\
\hline Tiene la mejor producción nacional & $45 \%$ & $24 \%$ & $11 \%$ & $6 \%$ & $22 \%$ & $4 \%$ & $8 \%$ & $3 \%$ & $2 \%$ & $3 \%$ & $3 \%$ \\
\hline Tiene los mejores programas deportivos & & $25 \%$ & $12 \%$ & $5 \%$ & $6 \%$ & $3 \%$ & $7 \%$ & $2 \%$ & $27 \%$ & $2 \%$ & $2 \%$ \\
\hline Es con el que usted se identifica & $39 \%$ & $24 \%$ & $16 \%$ & $6 \%$ & $14 \%$ & $3 \%$ & $7 \%$ & $3 \%$ & $4 \%$ & $2 \%$ & $2 \%$ \\
\hline Es un canal que transmite valores & $24 \%$ & $15 \%$ & $10 \%$ & $8 \%$ & $32 \%$ & $7 \%$ & $14 \%$ & $4 \%$ & $2 \%$ & $3 \%$ & $2 \%$ \\
\hline Es el canal líder & $49 \%$ & $25 \%$ & $13 \%$ & $5 \%$ & $9 \%$ & $3 \%$ & $6 \%$ & $2 \%$ & $3 \%$ & $1 \%$ & $1 \%$ \\
\hline
\end{tabular}

Figura 19. Atributos de canales de TV Nacional. IPSOS(2018)

\section{RADIO}




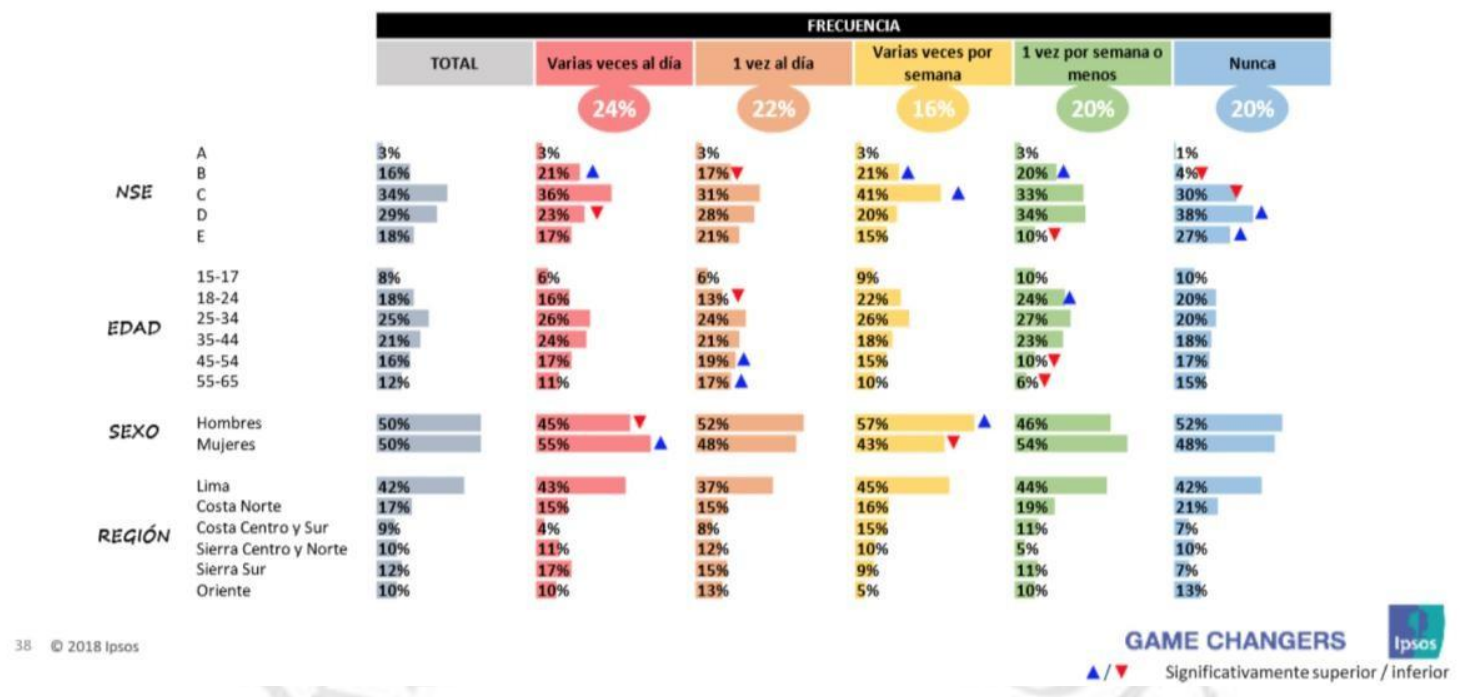

Respecto a la radio, el NSE C Y D sintoniza varias veces al día y durante la semana en un $36 \%$ y $23 \%$ respectivamente. Asimismo, de acuerdo a los millennials de 25 a 34 años, su alcance es de $26 \%$

\section{$\mathrm{OOH}$}

Respecto a la publicidad exterior, el NSE C consume varias veces al día OOH en un 35 $\%$ mientras que el NSE D en un 25\%. Asimismo, los millennials de 25 a 34 años consumen $\mathrm{OOH}$ en un $28 \%$.

\section{PERFIL DE CONSUMIDORES}

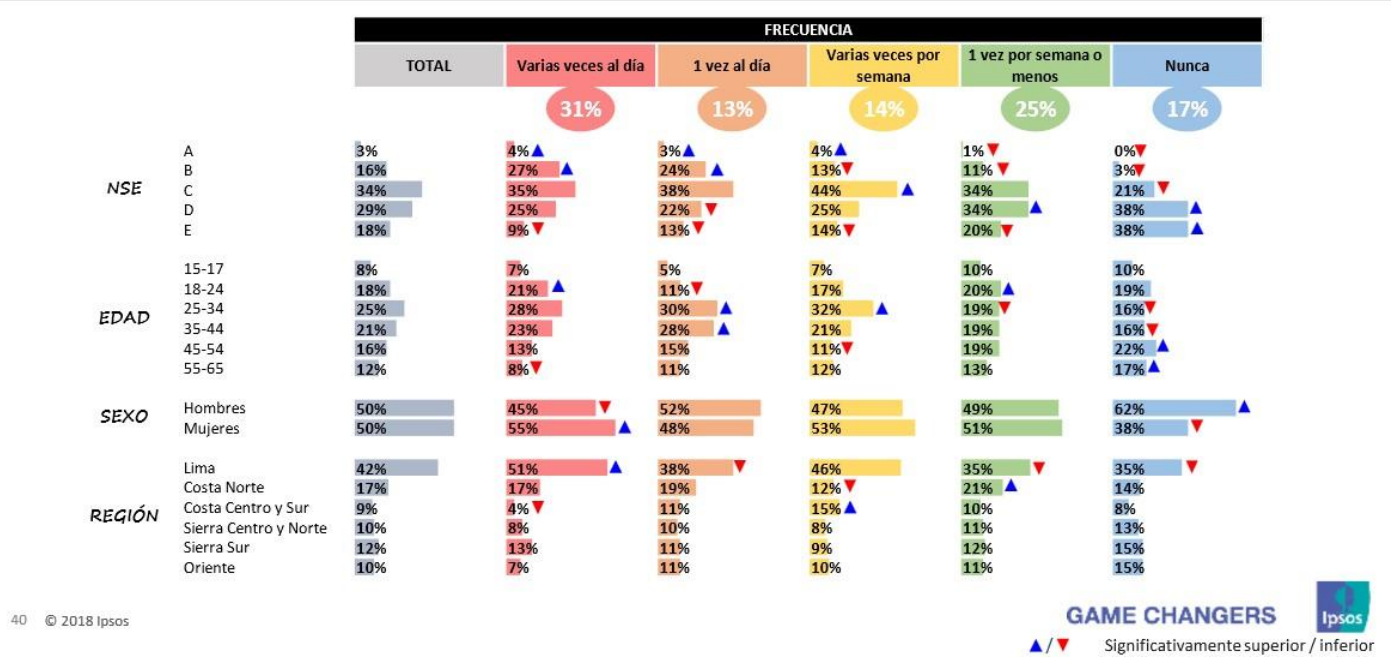

Figura 20.Perfil de consumidores. IPSOS(2018)

\section{Digital}


El NSE C consume YouTube en 4:55 horas en promedio semanal, mientras que el NSE D en 2:44 horas. Por otro lado, los millennials de 25 a 34 años de edad consumen en promedio semanal Facebook en 5:00 horas.

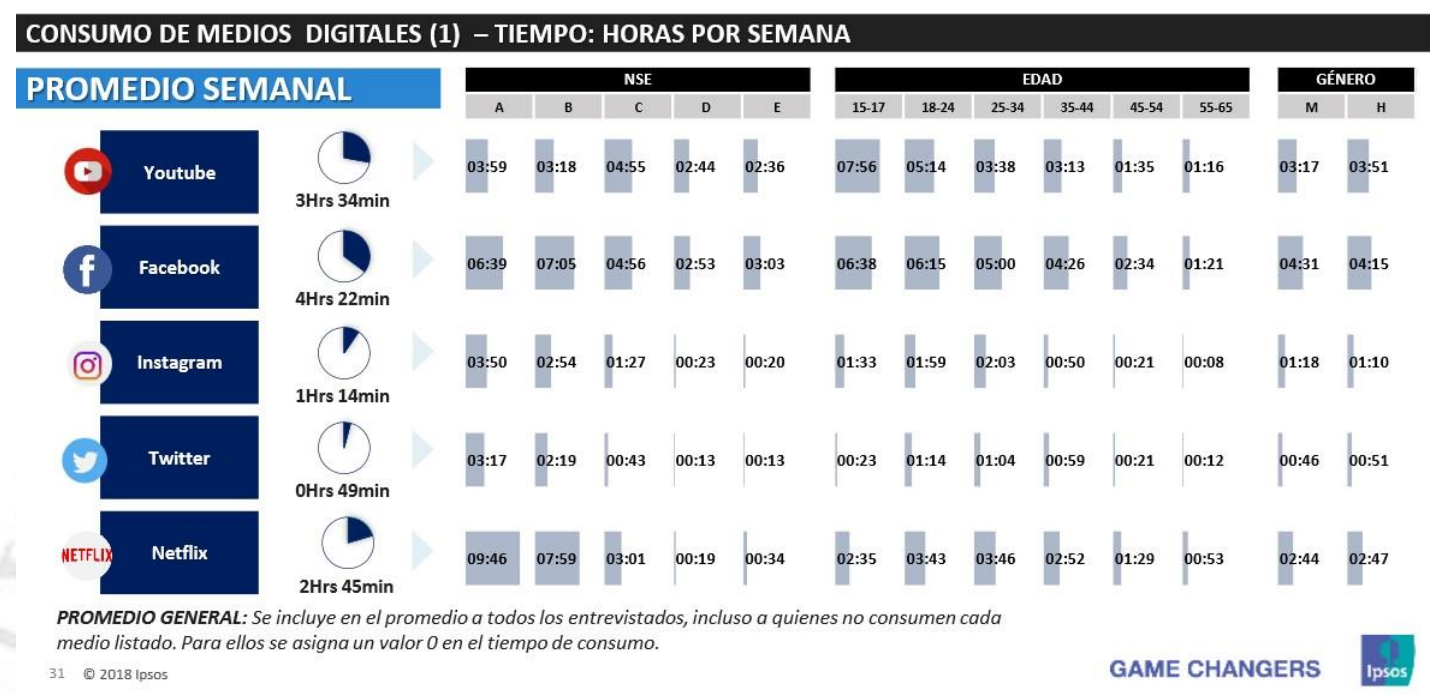

Figura 21.Consumo de medios digitales. IPSOS(2018)

\section{Facebook}

El NSE C consume varias veces al día Facebook en un $38 \%$ mientras que el NSE D en un $18 \%$. Asimismo, los millennials de 25 - 34 años consume esta red social en un $25 \%$ varias veces al día.

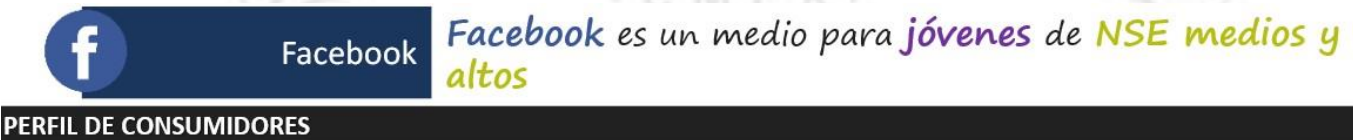

\begin{tabular}{|c|c|c|c|c|c|c|c|}
\hline \multicolumn{8}{|c|}{ PERFIL DE CONSUMIDORES } \\
\hline & & TOTAL & Varias veces al dia & 1 vez al día & $\begin{array}{c}\text { Varias veces por } \\
\text { semana }\end{array}$ & $\begin{array}{c}1 \text { vez por semana o } \\
\text { menos }\end{array}$ & Nunca \\
\hline \multirow{5}{*}{ NSE } & A & $3 \%$ & $5 \% \Delta$ & $3 \% \mathbf{\Lambda}$ & $2 \%$ & $1 \% \nabla$ & $0 \% \mathrm{~V}$ \\
\hline & B & $16 \%$ & $29 \%$ & $18 \%$ & $10 \%$ & $12 \% \mathrm{~V}$ & $1 \%$ \\
\hline & c & $34 \%$ & $38 \%$ & $40 \%$ & $53 \%$ & $23 \% \nabla$ & $20 \% \nabla$ \\
\hline & D & $29 \%$ & $18 \% \nabla$ & $\begin{array}{l}20 \% \\
20 \%\end{array}$ & $27 \%$ & $38 \%$ & $48 \%$ \\
\hline & $\mathrm{E}$ & $18 \%$ & $10 \%$ & $19 \%$ & $8 \% \bar{V}$ & $26 \% \triangle$ & ${ }_{31 \%}^{48 \%} \backslash$ \\
\hline \multirow{6}{*}{ EDAD } & $15-17$ & $8 \%$ & $11 \% \Delta$ & $11 \% \wedge$ & $9 \%$ & $8 \%$ & $2 \% \mathrm{~V}$ \\
\hline & $18-24$ & $18 \%$ & $25 \%$ & $17 \%$ & $16 \%$ & $23 \%$ & $8 \% \nabla$ \\
\hline & $25-34$ & $25 \%$ & $33 \% \quad \Delta$ & $24 \%$ & $23 \%$ & $22 \%$ & $14 \% \mathrm{~V}$ \\
\hline & $35-44$ & $21 \%$ & $20 \%$ & $26 \%$ & $25 \%$ & $21 \%$ & $17 \%$ \\
\hline & $45-54$ & $16 \%$ & $7 \% \mathrm{~V}$ & $16 \% \mathrm{~V}$ & $20 \%$ & $17 \%$ & $28 \% \quad \Delta$ \\
\hline & $55-65$ & $12 \%$ & $4 \% \bar{V}$ & $6 \% \bar{\gamma}$ & $7 \% \nabla$ & $9 \% \mathrm{~V}$ & $31 \% \quad \bar{\Delta}$ \\
\hline \multirow{2}{*}{ SEXO } & Hombres & $50 \%$ & $47 \%$ & $55 \%$ & $56 \%$ & $55 \%$ & $46 \%$ \\
\hline & Mujeres & $50 \%$ & $53 \%$ & $45 \%$ & $44 \%$ & $45 \%$ & $54 \%$ \\
\hline \multirow{6}{*}{ REGIÓN } & Lima & $42 \%$ & $\Delta$ & $42 \%$ & $49 \%$ & $24 \% \mathrm{~V}$ & $28 \% \nabla$ \\
\hline & Costa Norte & $17 \%$ & $16 \%$ & $23 \%$ & $13 \%$ & $21 \%$ & $16 \%$ \\
\hline & Costa Centro y Sur & $9 \%$ & $6 \%$ & $5 \%$ & $12 \%$ & $14 \%$ & $11 \%$ \\
\hline & Sierra Centro y Norte & $10 \%$ & $9 \%$ & $10 \%$ & $6 \%$ & $12 \%$ & $12 \%$ \\
\hline & Sierra Sur & $12 \%$ & $9 \%$ & $10 \%$ & $13 \%$ & $14 \%$ & $17 \%$ \\
\hline & Oriente & $10 \%$ & $6 \%$ & $10 \%$ & $7 \%$ & $15 \%$ & $16 \%$ \\
\hline
\end{tabular}


Figura 22.Perfil de Consumidores-Facebook. IPSOS(2018)

\section{YouTube}

El NSE C consume varias veces al día YouTube en un $40 \%$ mientras que el NSE D en un $12 \%$. Asimismo, los millennials de 25 - 34 años consume esta red social en un $33 \%$ varias veces al día.

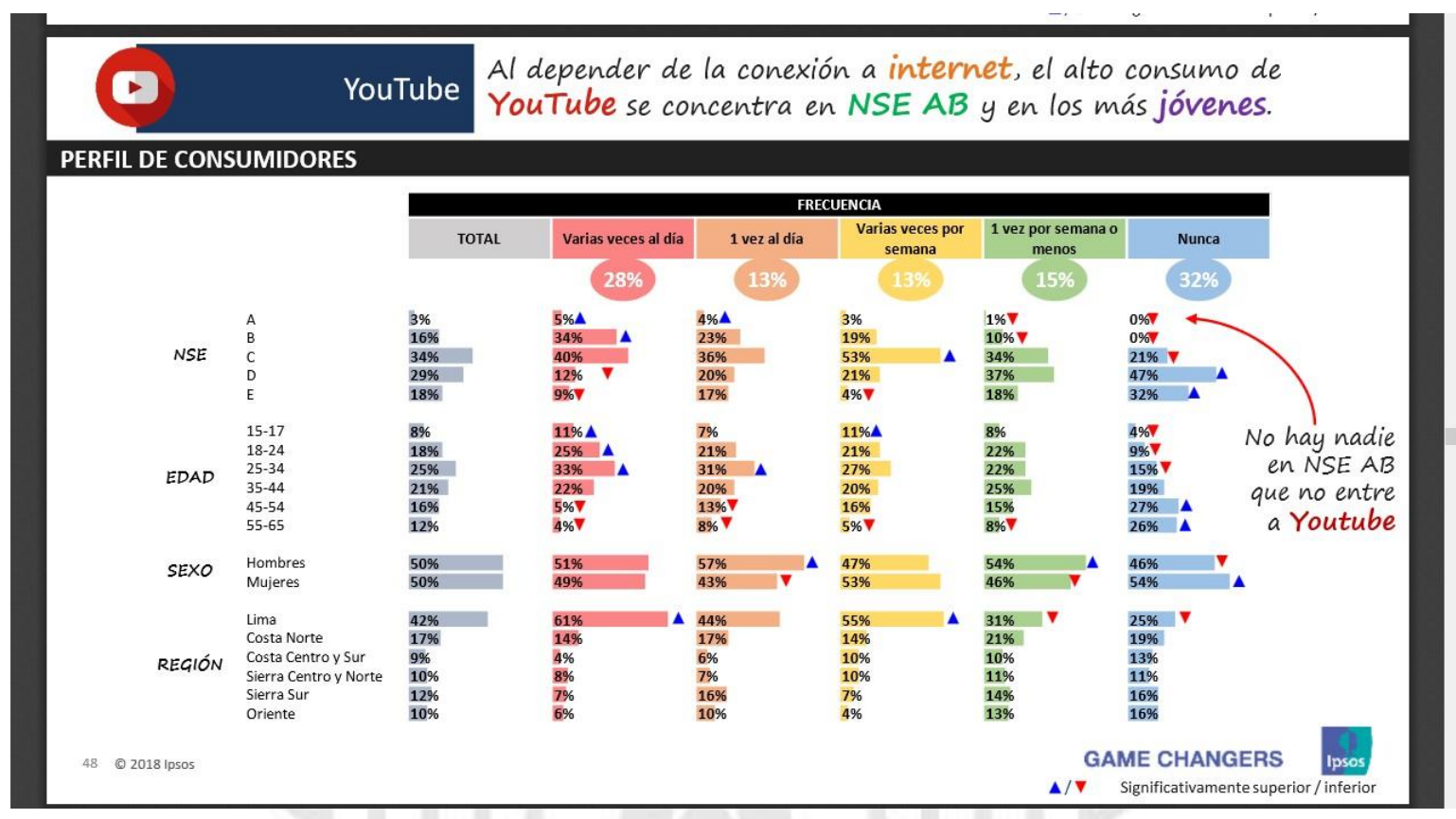

Figura 23.Perfil de Consumidores- Youtube. IPSOS(2018)

\section{Instagram}

El NSE C consume varias veces al día Instagram en un $42 \%$ mientras que el NSE D en un 10\%. Asimismo, los millennials de 25 - 34 años consume esta red social en un $40 \%$ varias veces al día. 


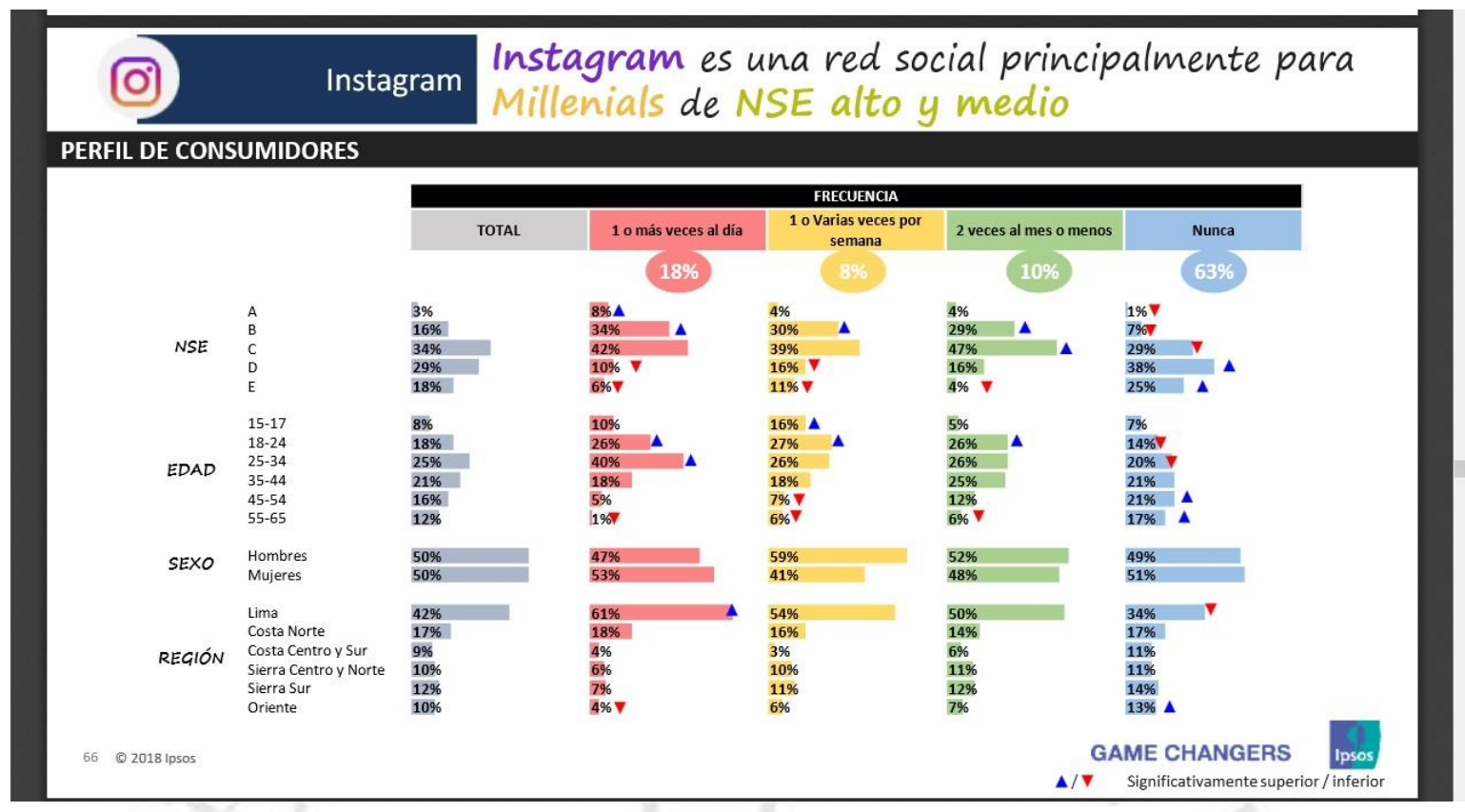

Figura 24.Perfil de Consumidores- Instagram. IPSOS(2018)

\section{Punto de Venta}

El NSE C está expuesto varias veces al día a la publicidad de punto de venta en un $37 \%$ mientras que el NSE D en un 21\%. Asimismo, los millennials de 25 - 34 años están expuestos a este medio en un $28 \%$ varias veces al día.

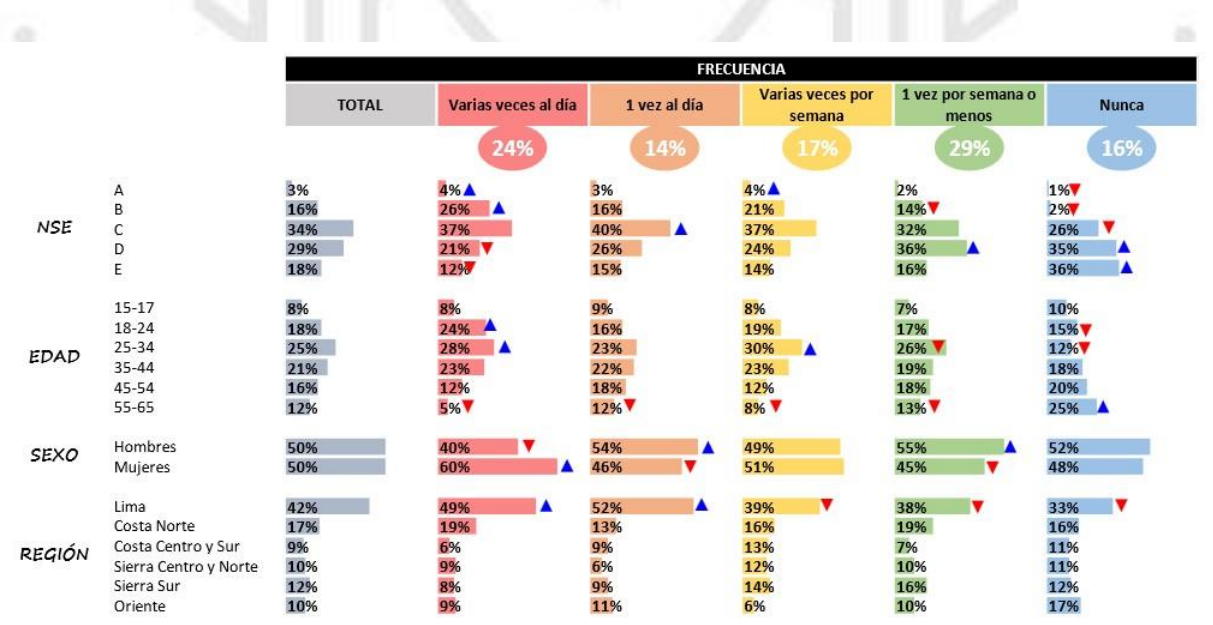

Figura 25.Frecuencia consumo TV. IPSOS(2018) 


\section{Campaña de lanzamiento}

\section{TV y Digital}

Influenciadores:

De los ganadores peruanos de los juegos panamericanos 2019, seleccionamos 5 principales influencers:

- Gladys Tejeda

- Christian Pacheco

- Benoit Piccolo

- Alexandra Grande

- Pilar Jáuregui

Realizamos un spot llamado "Vive como Campeón", en donde se ve a dos periodistas preguntando a los ganadores qué es lo mejor de ser un campeón.

\section{GUIÓN TV}

Gladys aparece corriendo mientras algunos reporteros y periodistas se acercan a ella

Reportero: Dinos Gladys, ¿qué es lo mejor de ser un campeón?

Gladys(sonriendo): Bueno, que puedo decir. Ahorro más en luz y en agua

Reportero (se queda sorprendido sorprendido por la respuesta)

Pacheco (pasa caminando): Pero no sólo eso, es poder ejercitarse todas las mañanas en una gran pista deportiva

(mientras habla mira la pista de trote)

Se acerca Piccolo: para mí es poder relajarse en la piscina

(Disolvencia negro)

\section{Piccolo aparece nadando}

Viene Alexandra Grande: Tener gimnasio incluido

(Disolvencia negro)

\section{Vemos a Alexandra entrenando}

Viene Jáuregui: Pero sobre todo comodidades y facilidades para poder entrenar 
(Disolvencia negro)

se le ve saliendo del pasadizo al exterior

Voz en off: ¿ Y tú qué esperas?

Disfruta de los departamentos de Villa Panamericanos y aprovecha la oportunidad para vivir como un campeón

Infórmate sobre las modalidades de financiamiento con Mivivienda en Besco emprendedor.

Contáctanos al 016373200 e infórmate en $\underline{\text { www.bescoemprendedor.com }}$

\section{STORYBOARD}
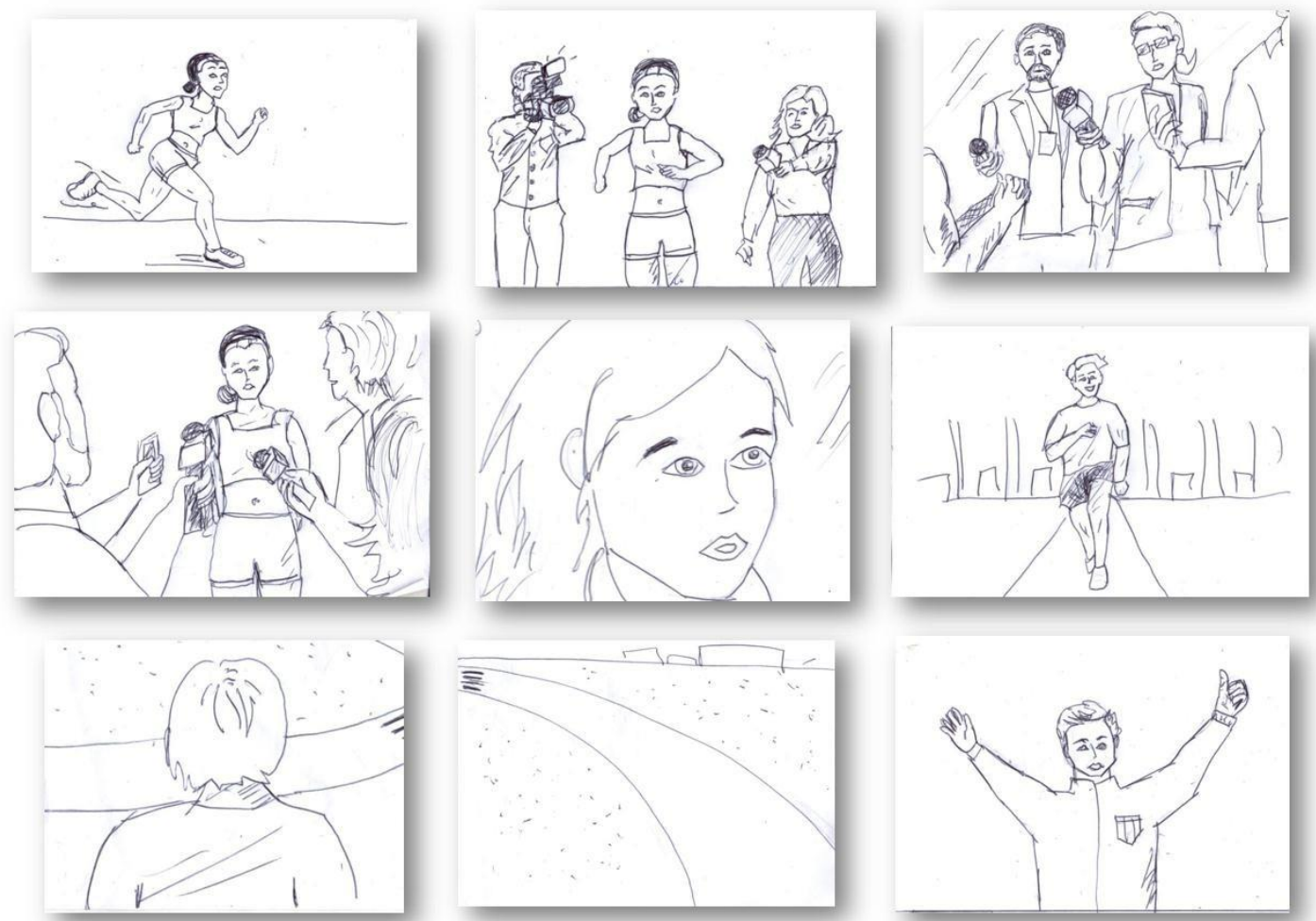

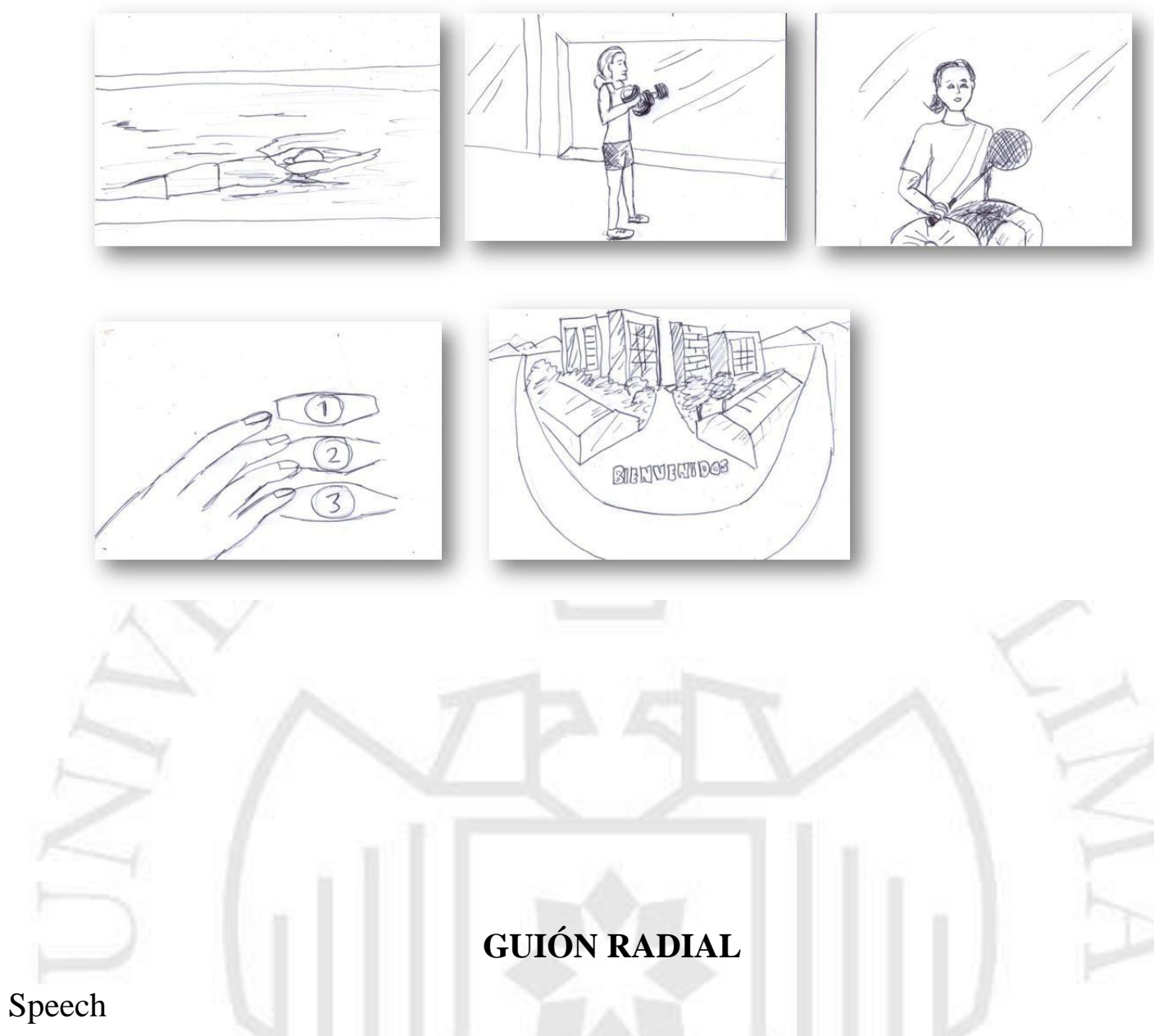

¿Quieres vivir como campeón?

¡Adquiere tu departamento en Villa Panamericanos!

Ingresa a www.bescoemprendedor.com, regístrate y disfruta de los verdaderos beneficios de un campeón.

¡No te lo puedes perder, están increíbles!

\section{POST FACEBOOK E INSTAGRAM:}

Definimos tres categorías de contenido a comunicar en las redes sociales:

- Post comercial

- Post inclusivo

- Post ecoamigable 


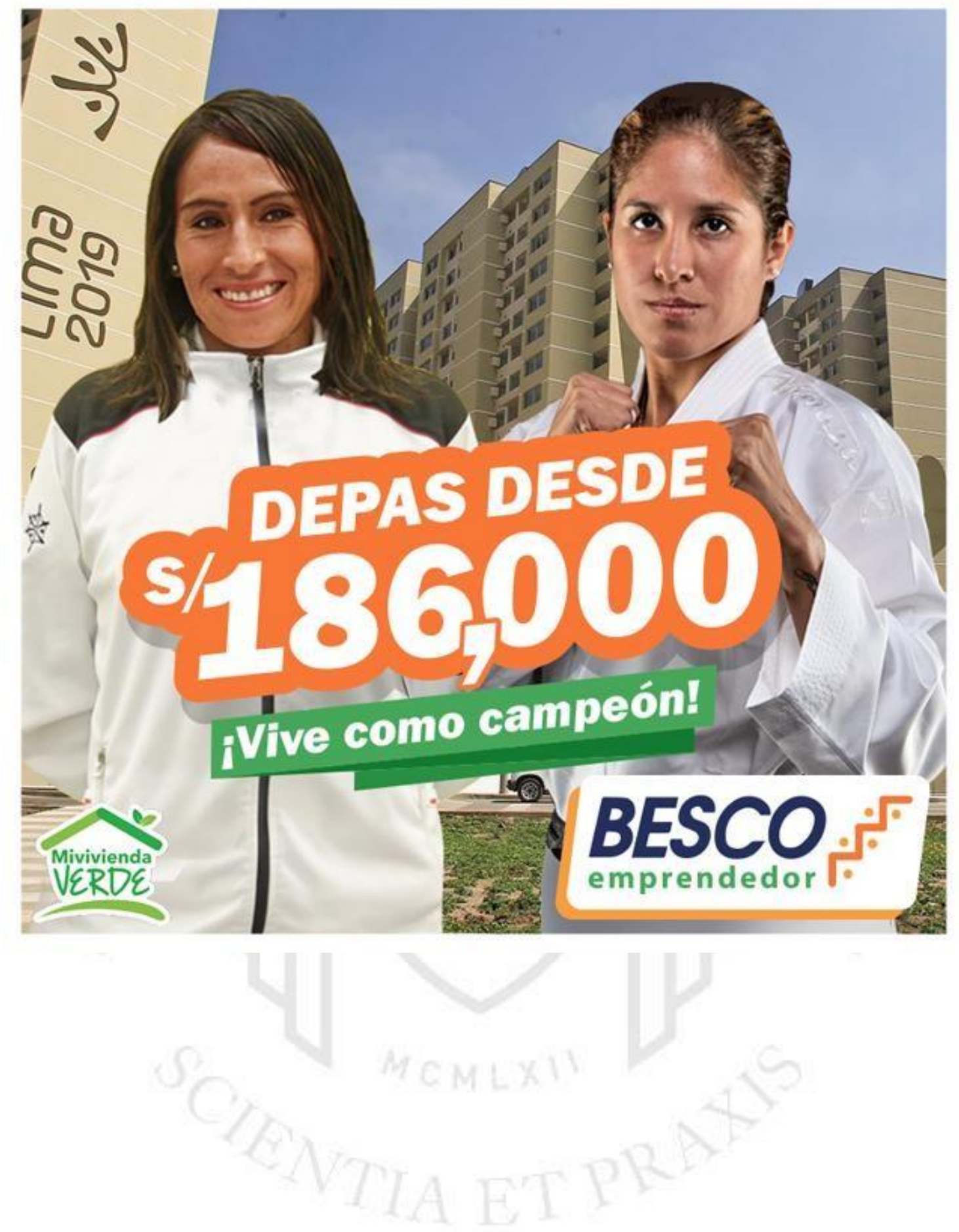




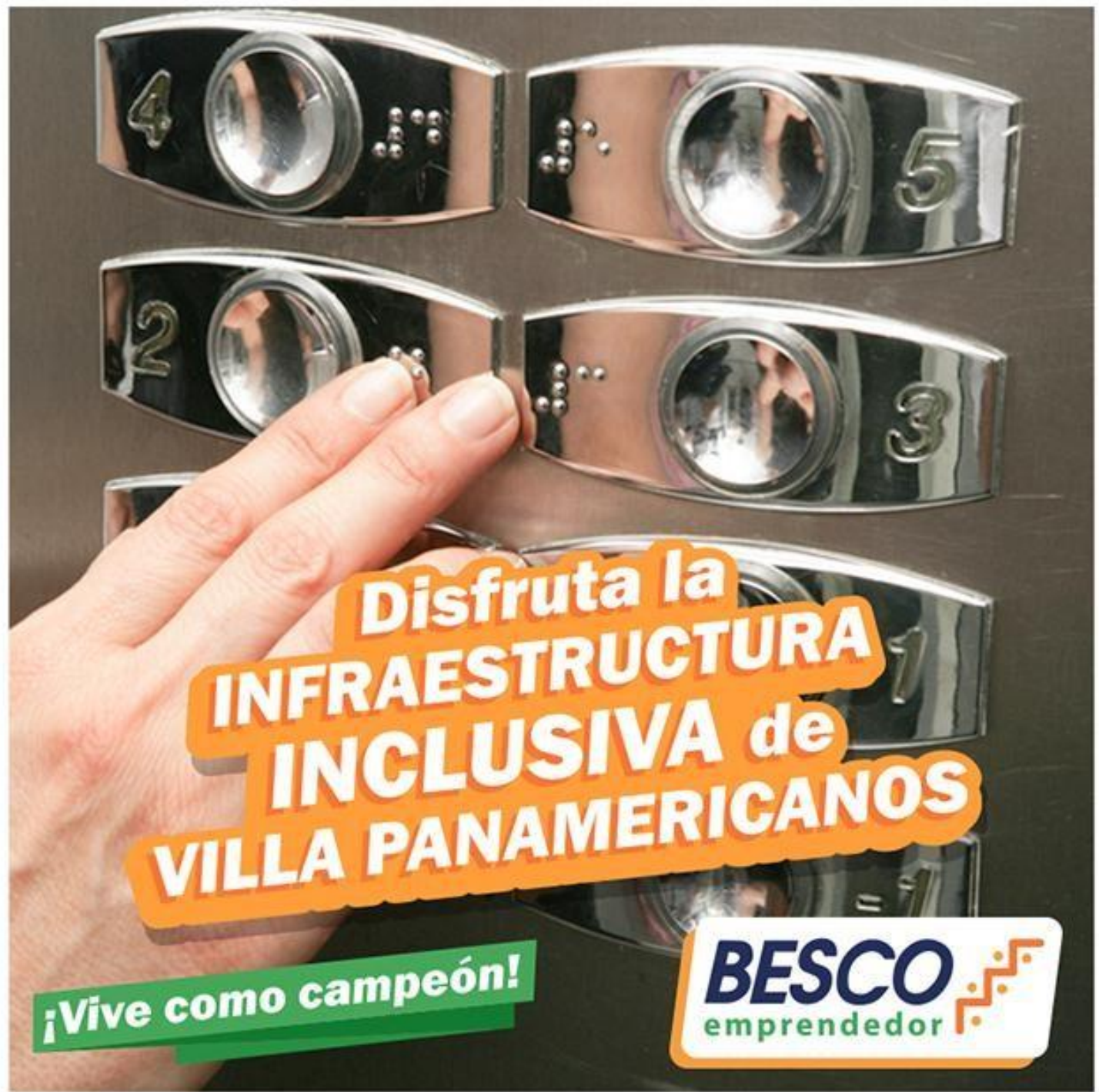




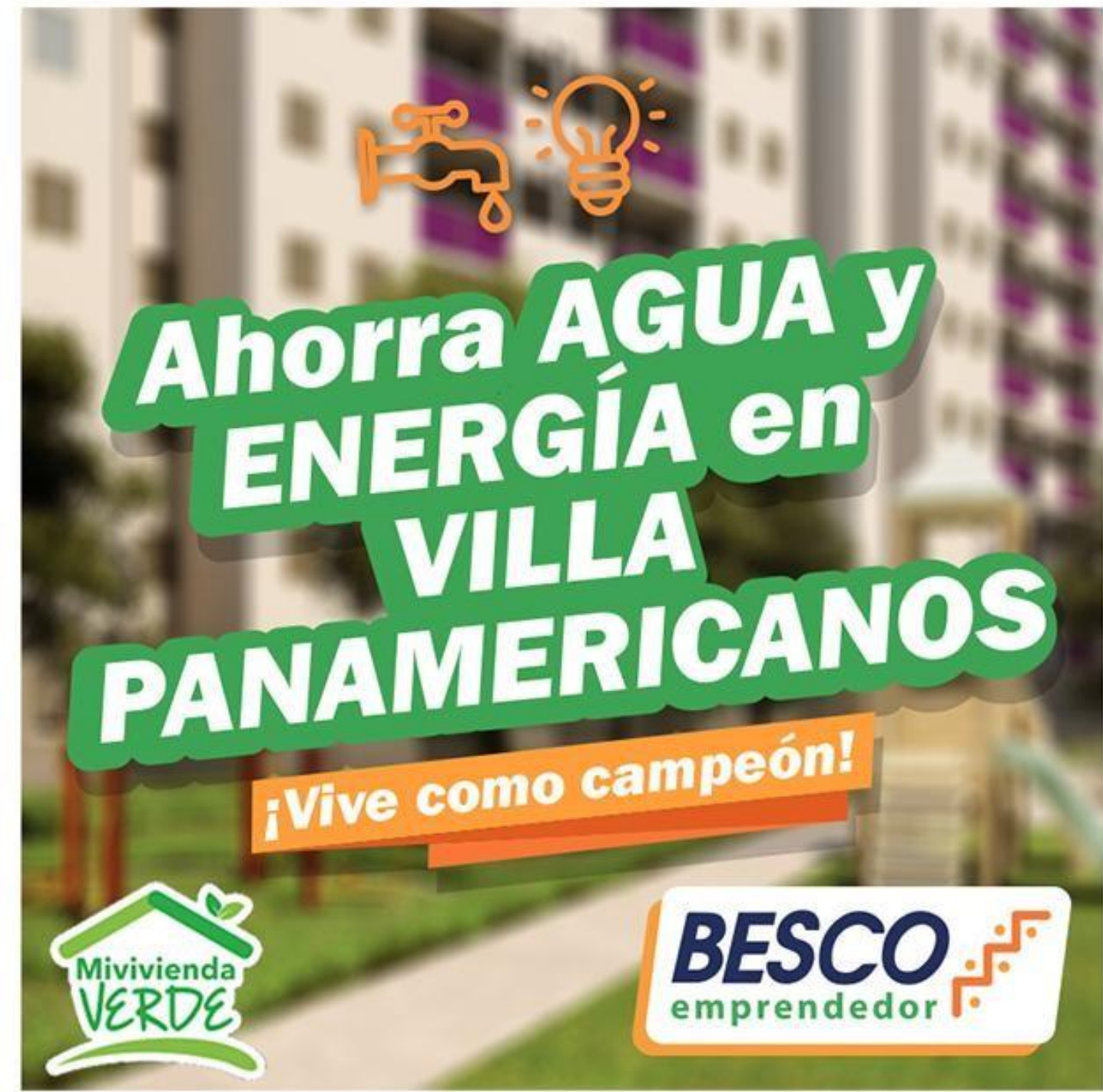

\section{OOH}

Paneles y Vallas:

Comunicaremos cerca a centros comerciales y parques representativos e hipermercados el concepto de vivir como ganador. 

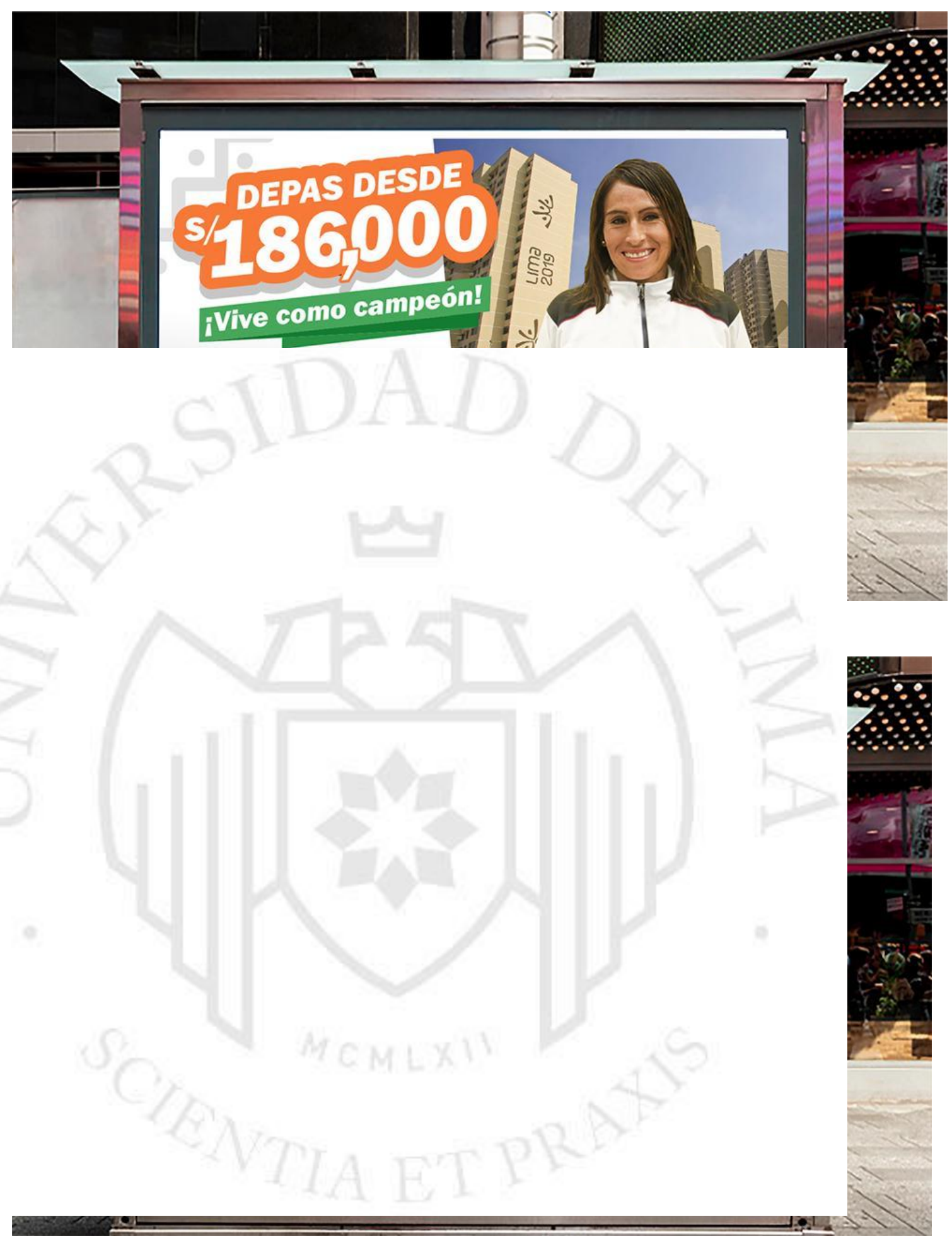


\section{LANDING PAGE}

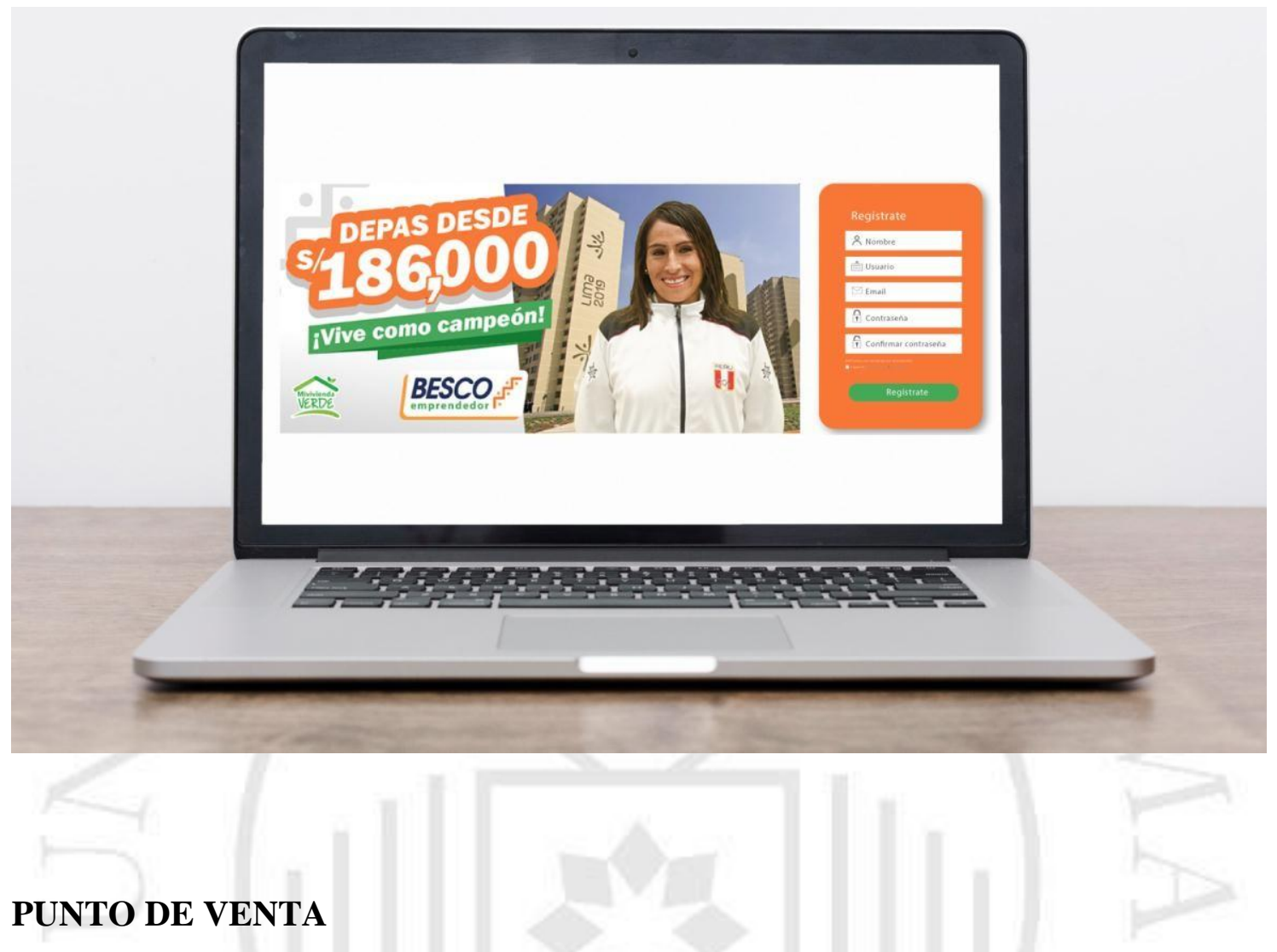

Ofreceremos la venta de departamentos de "Villa Panamericanos" en los centros comerciales:

- Plaza Norte

- Mall del Sur

- Mega Plaza 


\section{(⿹) BESCO}

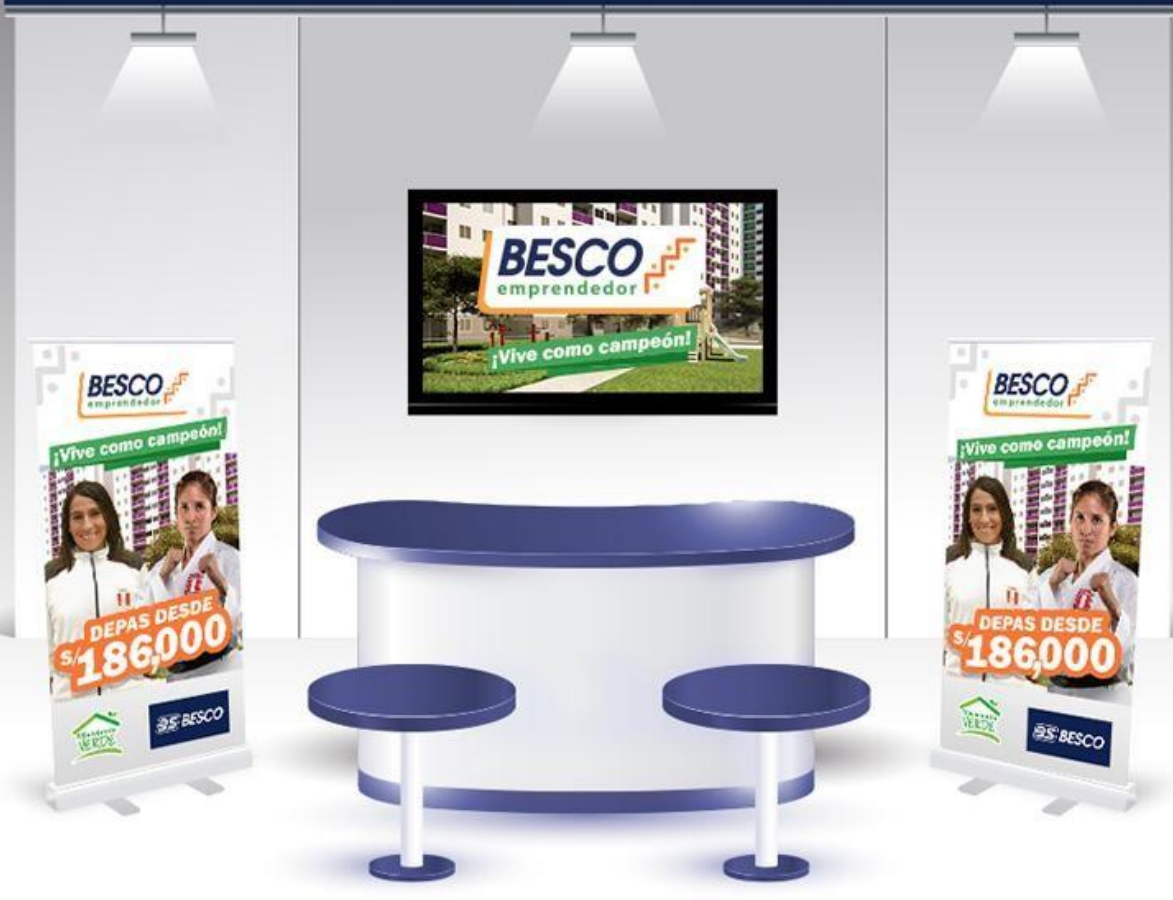

\section{DISTRIBUCIÓN DE INVERSIÓN DE CAMPAÑA}

La distribución de medios que elegimos es la siguiente:

\section{Distribución de medios}

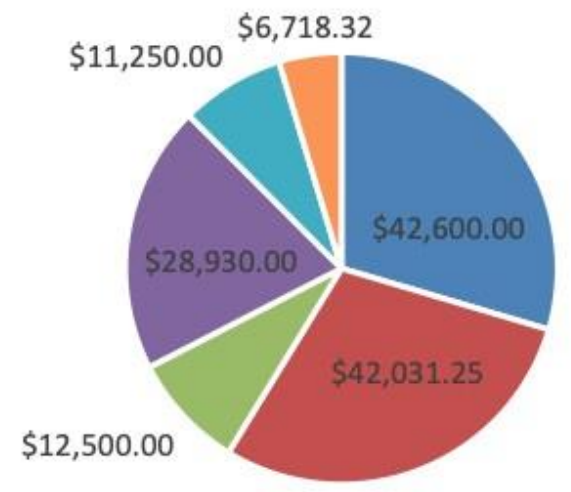

- TV $=\mathrm{OOH}$ - Producción - Digital $=$ Radio $=$ Punto de Venta 
Figura 26. Share de Inversión de la Campaña. Elaboración propia

Ver aquí el desglose de inversión y calendario de campaña:

https://drive.google.com/drive/folders/1KzLS1OAADskrIA90TBq8MarSSAtP1SLj?fbc lid=IwAR2kM0YzD326WhEAptBkuh9KSBP66EHp8pKi3LpSp3FcaBO13pbtiNzO02 $\underline{\mathrm{o}}$

\section{SUSTENTO DE PRESUPUESTO}

En ATL, específicamente en TV por ser el central medio de comunicación por preferencia de nuestro target realizamos una inversión de $\$ 42,600.00$.

En segundo lugar, toma protagonismo la publicidad exterior específicamente en vallas publicitarias en $\$ 42,031.25$. El consumo es de varias veces al día en $35 \%$ en el NSE C y $25 \%$ en el NSE D (IPSOS)

Por otro lado, incluimos la radio con una inversión de $\$ 11,250$ sabiendo que un buen porcentaje del público C D aún es un fiel oyente de este medio offline (IPSOS).

Respecto al ámbito digital, nuestro target usa como red central Facebook, el cual tiene una inversión de \$7000. El NSE C consume Facebook varias veces al día Facebook en un 38\% (IPSOS). Asimismo, nos enfocamos en otras redes sociales secundarias que frecuenta nuestro target como Youtube e Instagram. Asimismo, el uso de landing page, principales portales inmobiliarios e influencers (Urbania y Adondevivir) respecto a nuestro público objetivo, generando un total en inversión digital de $\$ 28,930.00$.

Por último, el punto de venta en centros comerciales genera una cotización de $\$ 6,718.32$ que estará presente durante los 6 meses que dure la campaña. NSE C está expuesto varias veces al día a la publicidad de punto de venta en un $37 \%$ mientras que el NSE D en un $21 \%$ (IPSOS) 


\section{CONCLUSIONES}

- Besco Emprendedor es una nueva línea de negocio de Besco BS, el cual tiene como meta vender los departamentos de la "Villa Panamericanos"

- Los principales atributos de los departamentos a comunicar es la característica de ecoamigable, ahorrativo, inclusivo y que son financiados con Mi Vivienda.

- La campaña busca generar valor emocional "Vive como Campeón" a los departamentos de "Villa Panamericanos" para que no se venda como commodity.

- Las piezas gráficas apuntan a desarrollar el concepto de cómo es vivir como un ganador comunicando así los atributos o beneficios "Villa Panamericanos"

\section{RECOMENDACIONES}

- Mantener la consistencia de la idea "Vive como Campeón" con otros ganadores de los panamericanos y parapanamericanos en los medios a anunciar.

- Priorizar los medios TV y Facebook ante un nuevo anuncio.

- Generar una miniserie digital "Reu de Propietarios" con todos los campeones para generar rebote en PR. 


\section{REFERENCIAS (Bibliografía)}

- Ley No 30952 (03 de Agosto del 2019) Publicación Oficial. Diario Oficial El Peruano https://busquedas.elperuano.pe/normaslegales/decreto-supremo-que-apruebareglamento-de-la-ley-n-30952-1-decreto-supremo-n-023-2019-vivienda1794200-1/

- Arellano (01 de Julio de 2019). Cruzados por la Panamabilidad Obtenido de Arellano: https://www.arellano.pe/cruzada-panamabilidad/

- Arellano (15 de Julio de 2019). Familias cambian de casa Obtenido de Arellano: https://www.arellano.pe/las-familias-cambian-de-casa

- BBVA RESEARCH (2008)

https://www.bbvaresearch.com/wpcontent/uploads/mult/revista_BBVA_sitiacion_inmobiliaria_tcm346189944.pdf

- BESCO S.A. (2019). Nuestra Historia. Obtenido de Besco: https://www.besco.com.pe/nosotros/historia/

- BESCO S.A. (2019). Valores. Obtenido de Besco: https://www.besco.com.pe/nosotros/valores/

- Diario Correo ( 07 de Agosto de 2019) https://diariocorreo.pe/opinion/los-panamericanos-de-la-politica-902850/

- El Comercio (28 de Junio de 2019) https://elcomercio.pe/politica/martin-vizcarra-panamericanos-lima-2019imaginen-haciamos-caso-predicadores-noticia-nndc659747?fbclid=IwAR0uMQRQqojh5JBv34pu8K8XzjWmPbITFokAXkQoCfeS sNaSQO4GXtbYLvc

- El Comercio (02 de Agosto de 2019) https://elcomercio.pe/lima/sucesos/juegos-panamericanos-lima-2019-piensanlimenos-ceremonia-inauguracion-plan-vial-primeros-dias-juegos-noticia-ecpm661037

- El Peruano (13 de Agosto de 2019) /https://elperuano.pe/noticia-1000-mllns-siguieron-lima-2019-82416.aspx 
- Gestión ( 28 de Junio de 2019)

https://gestion.pe/peru/politica/martin-vizcarra-panamericanos-imaginen-

hubiesemos-hecho-caso-predicadores-nndc-274443-noticia/

- IPSOS. (2018). Hábitos, usos y actitudes hacia el internet. IPSOS.

- IPSOS. (2018). Perfil del Adulto joven peruano. IPSOS.

- IPSOS. (2018). Consumo de Medios 2018.IPSOS.

- IPSOS. (2018). Medios de muy alto consumo. IPSOS.

- IPSOS. (2018). Evaluación de atributos - Marcas en medios de comunicación 2018.IPSOS.

- Macroconsult (2019). Reporte Económico "Perspectivas del sector inmobiliario" https://sim.macroconsult.pe/reporte-economico-perspectivas-del-sectorinmobiliario-2/

\section{ANEXOS}

A continuación, adjuntamos el drive donde se podrá ver el desglose de:

\section{Materiales:}

https://drive.google.com/drive/folders/1KzLS1OAADskrIA90TBq8MarSSAtP1SLj?fbc $\underline{\text { lid=IwAR2kM0YzD326WhEAptBkuh9KSBP66EHp8pKi3LpSp3FcaBO13pbtiNzO02 }}$ $\underline{\mathrm{o}}$

\section{Piezas de Comunicación:}

https://drive.google.com/drive/folders/1NNNuMq3T6NR_3cZk7kioiwn6Zafn2dQJ?fbcl id=IwAR2kM0YzD326WhEAptBkuh9KSBP66EHp8pKi3LpSp3FcaBO13pbtiNzO02o

\section{Manual de Marca:}

https://drive.google.com/drive/folders/17JRdhOSZa1hgySMf73gKkOsDfFotCDo?fbclid=IwAR2kM0YzD326WhEAptBkuh9KSBP66EHp8p Ki3LpSp3FcaBO13pbtiNzO020 